\title{
Modular Fluorescent Benzobis(imidazolium) Salts: Syntheses, Photophysical Analyses, and Applications
}

\author{
Andrew J. Boydston, Peter D. $\mathrm{Vu}^{\dagger}$, Olga L. Dykhno ${ }^{\dagger}$, Vicki Chang ${ }^{\dagger}$, Alvin R. Wyatt, $\mathrm{II}^{\dagger}$, Adam S. \\ Stockett, Eric T. Ritschdorff, Jason B. Shear, and Christopher W. Bielawski* \\ Department of Chemistry and Biochemistry, The University of Texas at Austin, Austin, TX 78712 \\ bielawski@cm.utexas.edu
}

\section{SUPPORTING INFORMATION}

Reference 24a: Xin, Z.; Serby, M. D.; Zhao, H.; Kosogof, C.; Szcaepankiewicz, B. G.; Liu, M.; BoLiu; Hutchins, C. W.; Sarris, K. A.; Hoff, E. D.; Falls, H. D.; Lin, C. W.; Ogiela, C. A.; Collins, C. A.; Brune, M. E.; Bush, E. N.; Droz, B. A.; Fey, T. A.; Knourek-Segel, V. E.; Shapiro, R.; Jaconson, P. B.; Beno, D. W. A.; Turner, T. M.; Sham, H. L.; Liu, G. J. Med. Chem. 2006, 49, 4459. 
$2 \cdot \mathrm{MeSO}_{4}^{\Theta}$
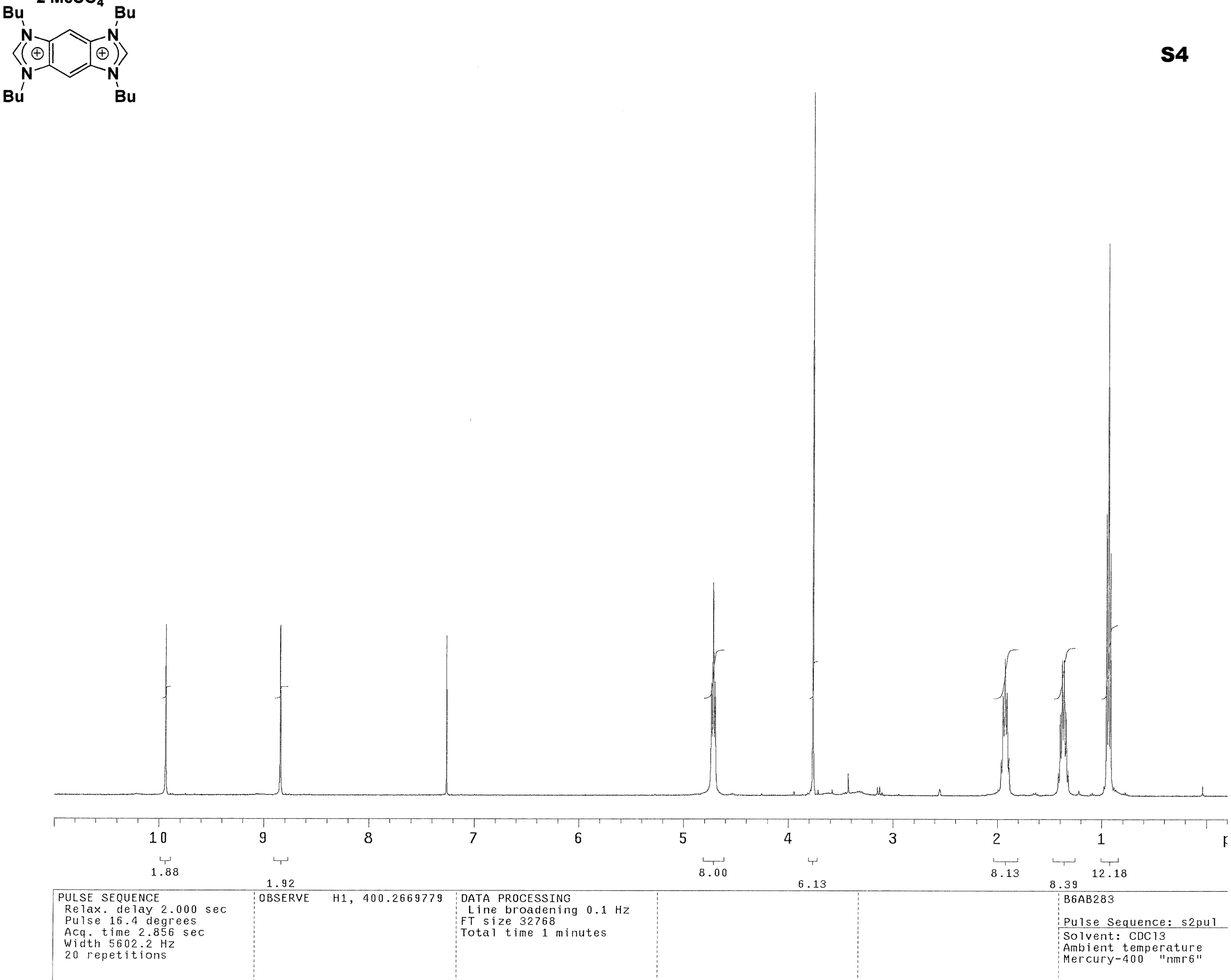

PULSE SEQUENCE

Relax. delay 2.000 sec

Pulse 16.4 degrees
Acq. time 2.856 sec

Width $5602.2 \mathrm{~Hz}$
20 repetitions

1.92

H1, 400.2669779 DATA PROCESSING

Line broadening $0.1 \mathrm{~Hz}$

Total time 1 minutes

Solvent: CDC 13

Mercury-400 "nmr6"
Mmbient temperature 
$2 \cdot \mathrm{MeSO}_{4}^{\Theta}$

$\mathrm{Bu} \quad \mathrm{Bu}$

N

$\left\langle\left(\oplus\left|\mathbf{N}_{\mathbf{N}}\right| \oplus\right)\right\rangle$

$\mathrm{Bu}$

$\mathrm{Bu}$

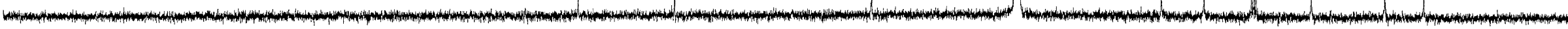

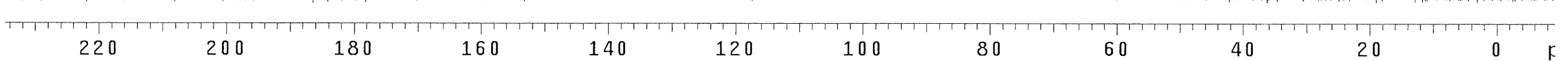

\begin{tabular}{|c|c|c|c|}
\hline \begin{tabular}{|l} 
PULSE SEQUENCE \\
Relax. delay $2.000 \mathrm{sec}$ \\
Pulse 22.5 degrees \\
Acq. time $1.280 \mathrm{sec}$ \\
Width $25188.9 \mathrm{~Hz}$ \\
10000 repetitions
\end{tabular} & $\begin{array}{l}\text { OBSERVE C13, } 100.6472184 \\
\text { DECOUPLE H1, } 400.2689955 \\
\text { Power } 38 \text { dB } \\
\text { conti nuous Iy on } \\
\text { WALTZ-16 modulated }\end{array}$ & $\begin{array}{l}\text { DATA PROCESSING } \\
\text { Line broadening } 1.0 \mathrm{~Hz} \\
\text { FT size } 65536 \\
\text { Total time } 9.1 \text { hours }\end{array}$ & $\begin{array}{l}\text { B6AB283+DMSO-13C } \\
\text { Pulse Sequence: s2pul } \\
\text { Solvent: CDC13 } \\
\text { Ambient temperature } \\
\text { Mercury- } 400 \text { "nmr6" }\end{array}$ \\
\hline
\end{tabular}


Ph
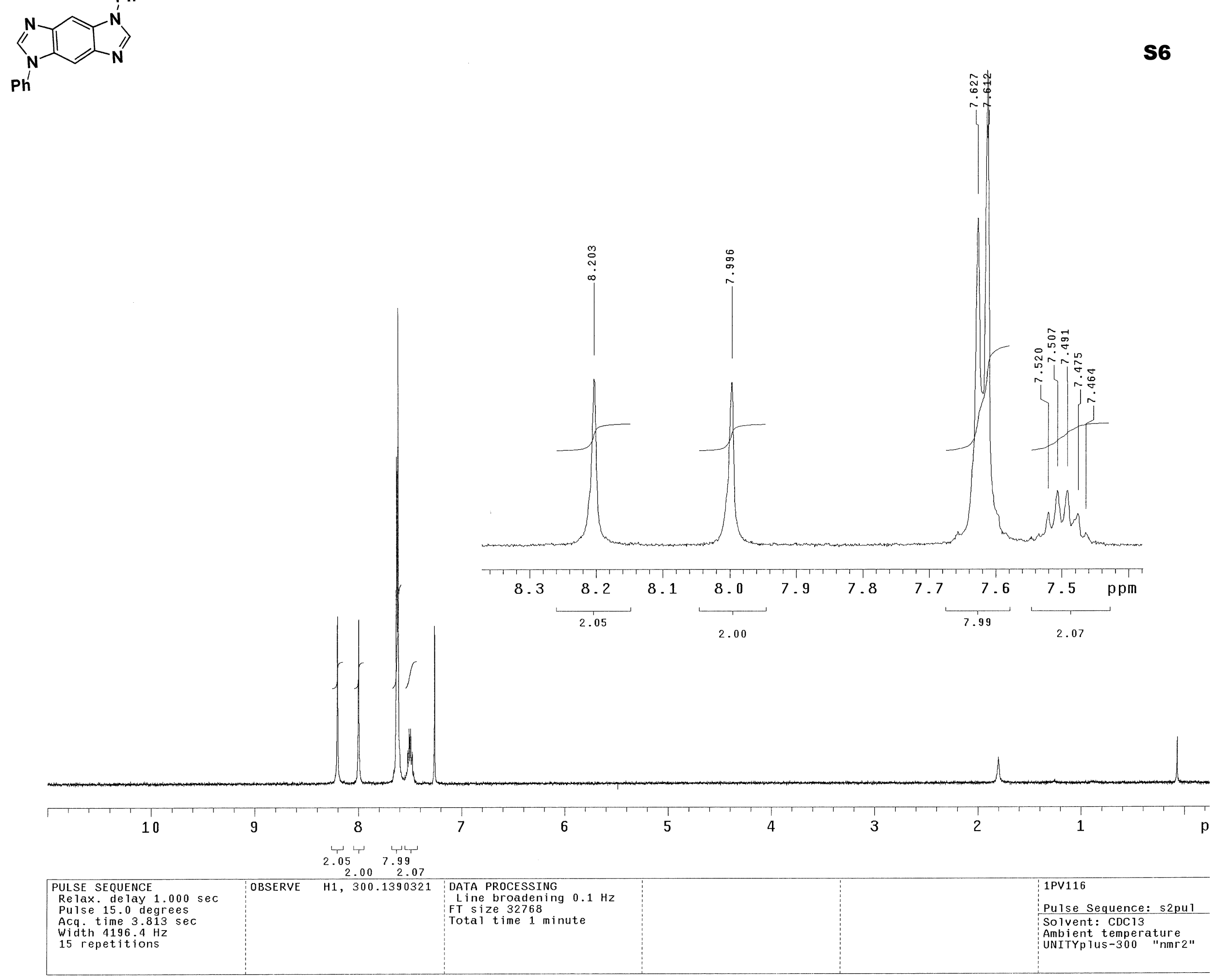


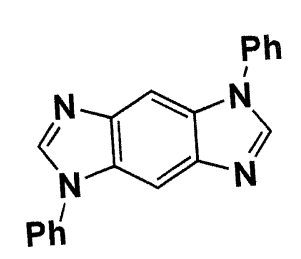

\section{S7}

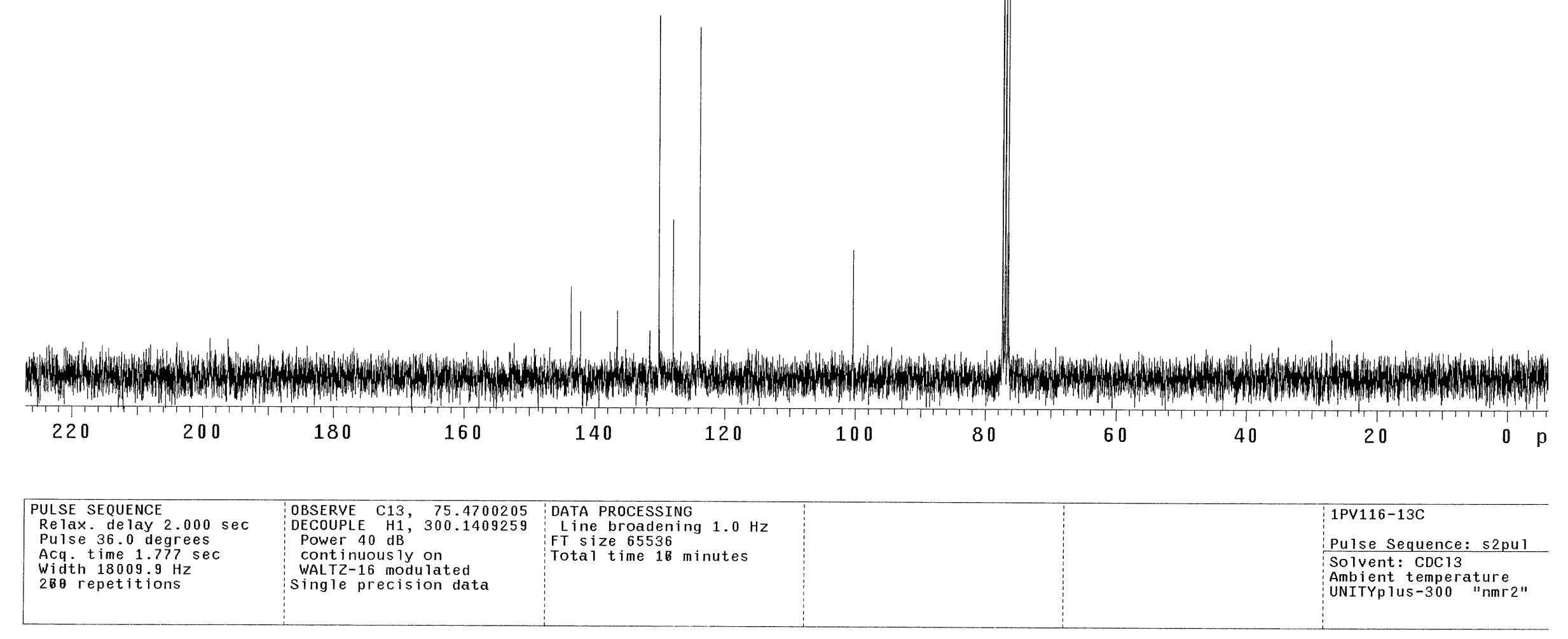



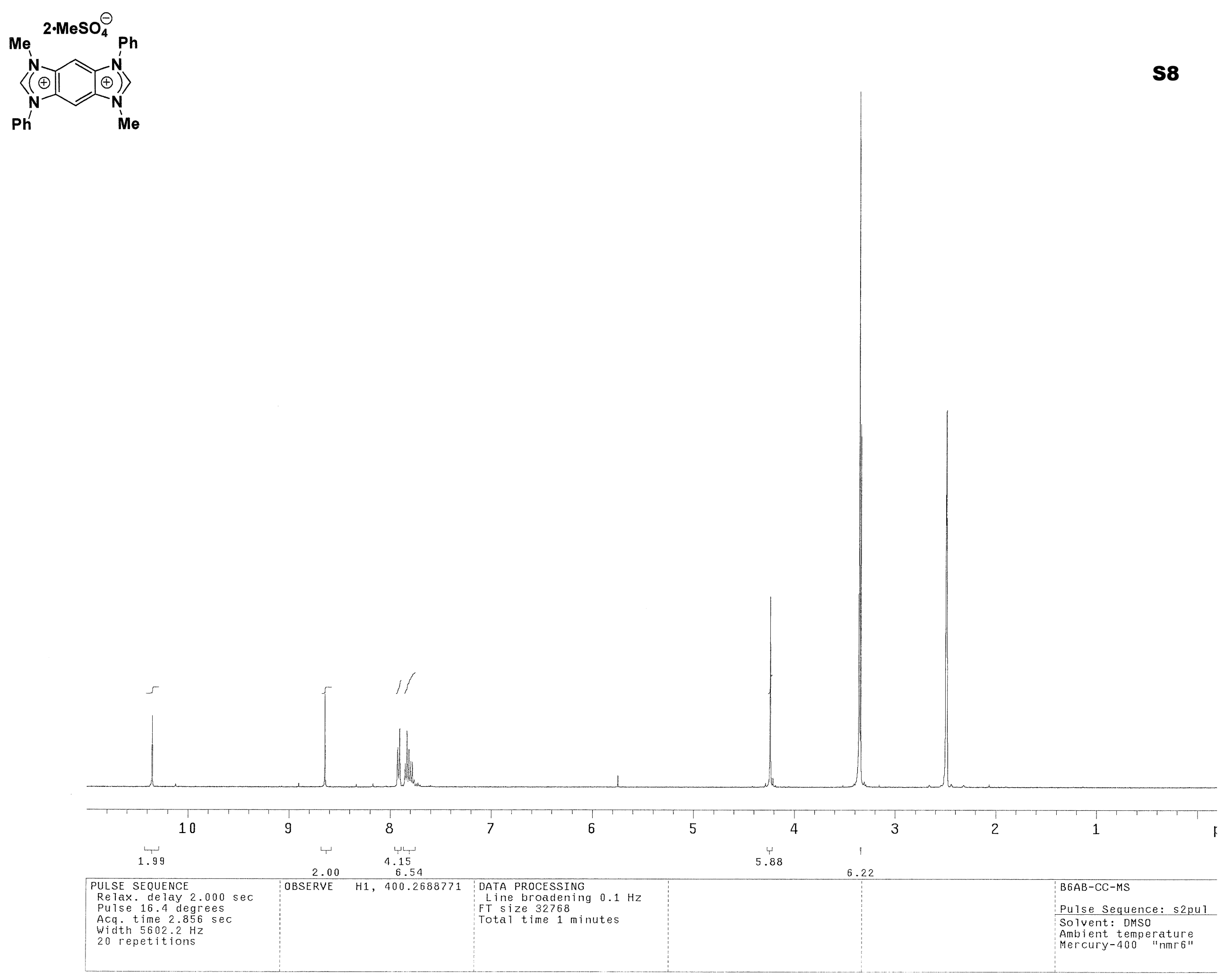


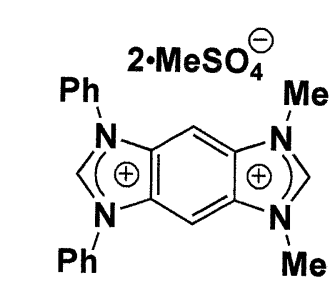

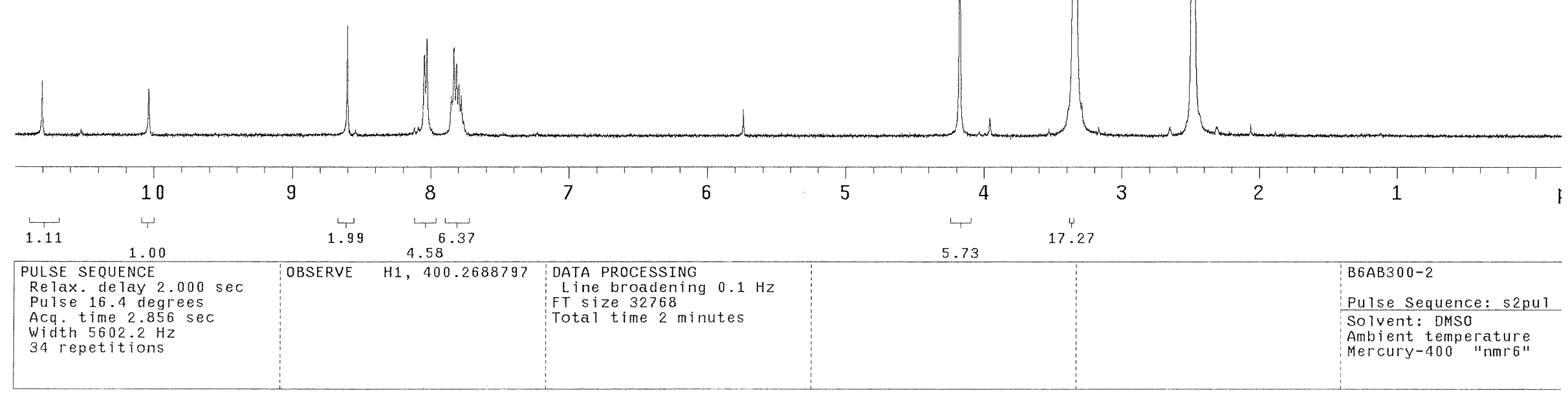



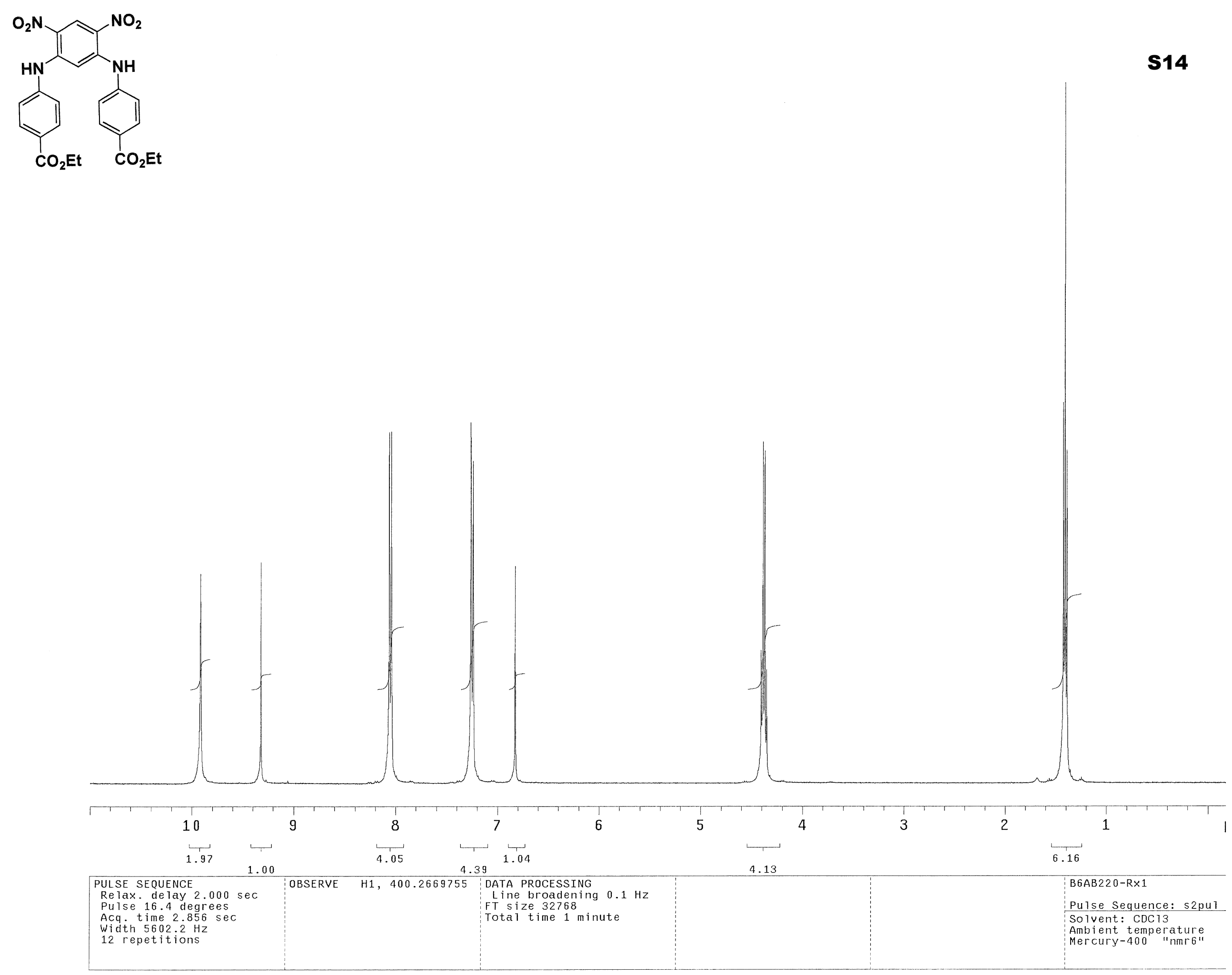


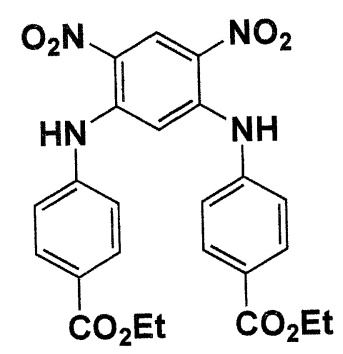

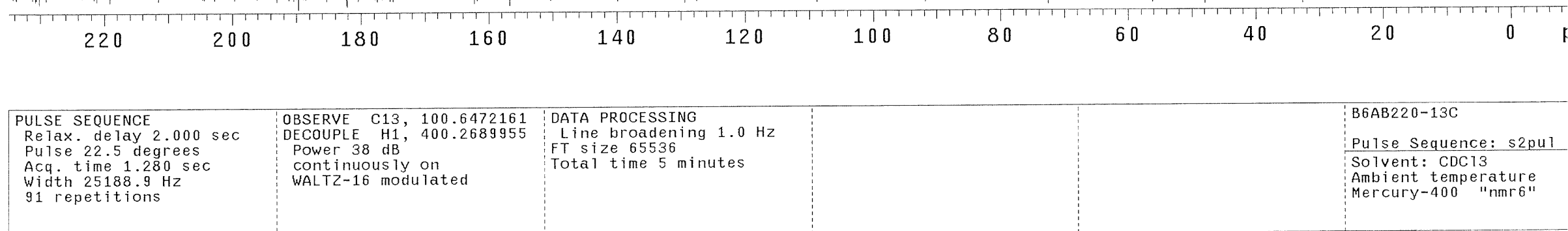



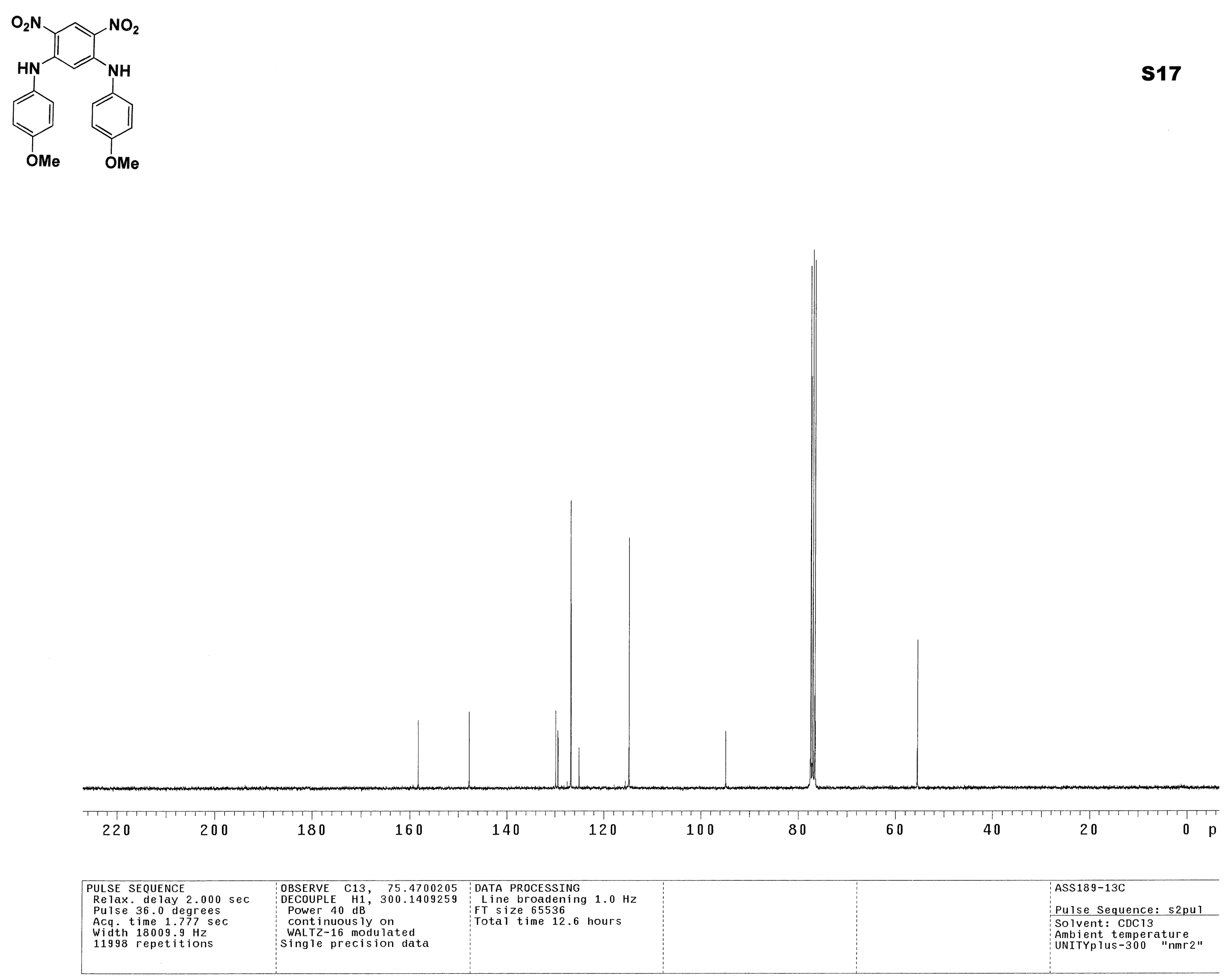

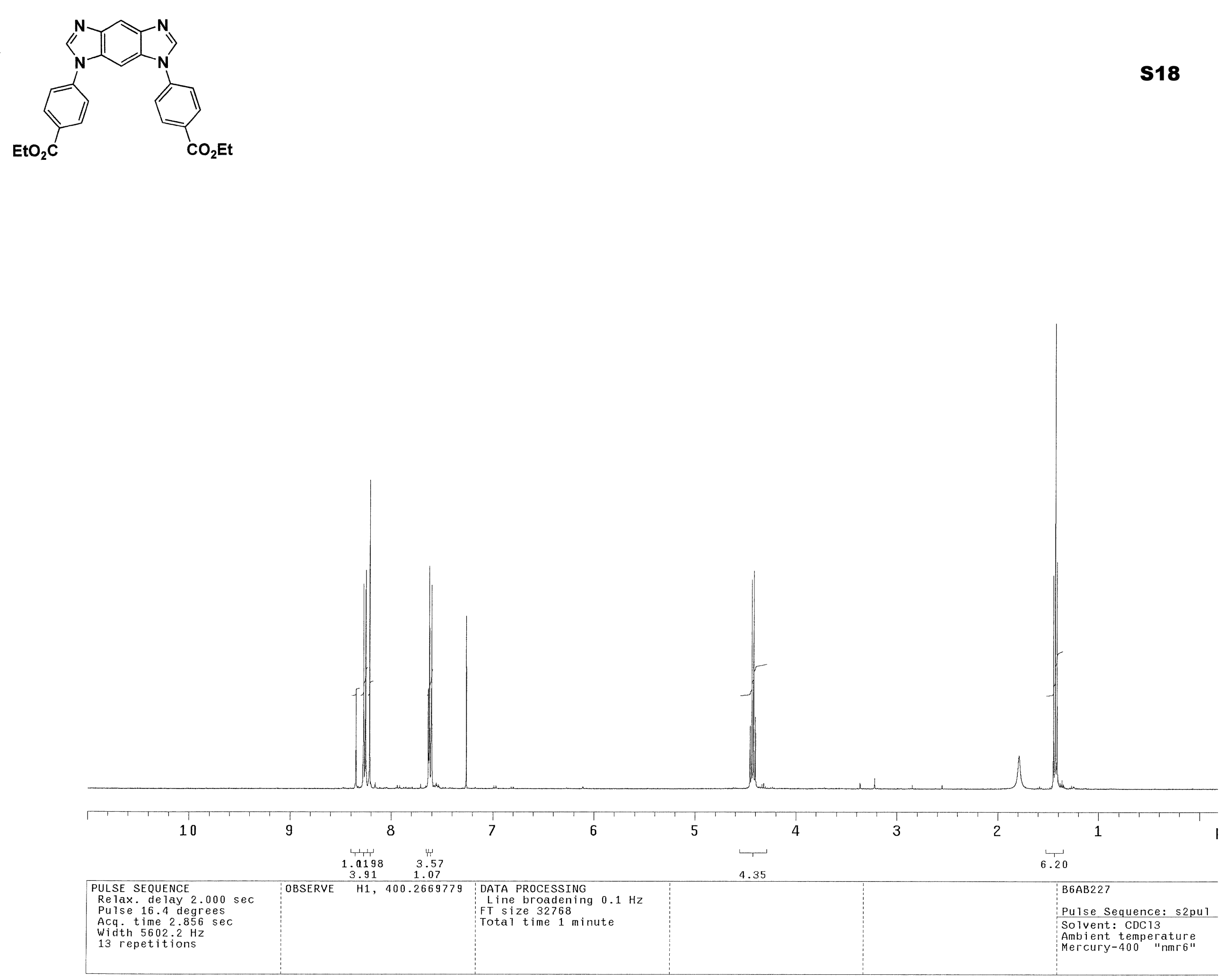


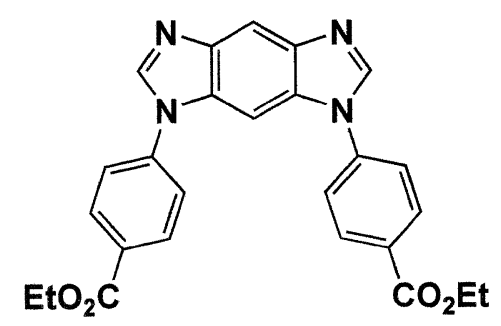

\begin{tabular}{|c|c|c|c|}
\hline $\begin{array}{l}\text { PULSE SEQUENCE } \\
\text { Relax. delay } 2.000 \mathrm{sec} \\
\text { Pulse } 36.0 \text { degrees } \\
\text { Acq. time } 1.777 \mathrm{sec} \\
\text { Width } 18009.9 \mathrm{~Hz} \\
464 \text { repetitions }\end{array}$ & $\begin{array}{l}\text { OBSERVE C13, } 75.4700211 \\
\text { DECOUPLE H1, } 300.1409259 \\
\text { POwer 40 dB } \\
\text { cont inuous Iy on } \\
\text { WALTZ-16 modulated } \\
\text { single precision data }\end{array}$ & $\begin{array}{l}\text { DATA PROCESSING } \\
\text { Line broadening } 1.0 \mathrm{~Hz} \\
\text { FT size } 65536 \\
\text { Total time } 29 \text { minutes }\end{array}$ & $\begin{array}{l}\text { B6AB227-13C } \\
\text { Pulse Sequence: s2pul } \\
\text { Solvent: CDC13 } \\
\text { Ambient temperature } \\
\text { UNITYplus }-300 \text { "nmr2" }\end{array}$ \\
\hline
\end{tabular}



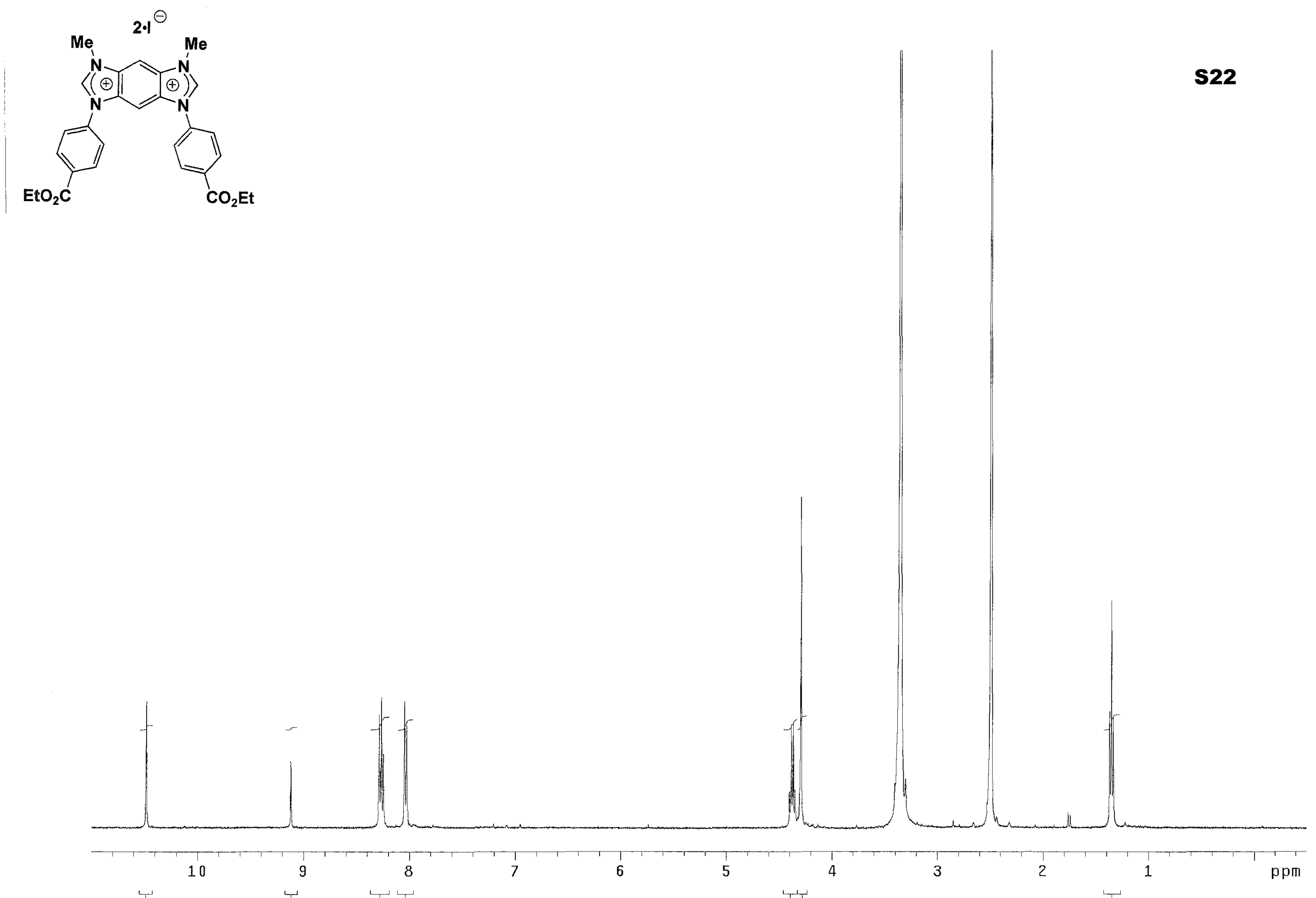

1.91 5.23

5.84
4.29
5.84

6.37

\begin{tabular}{|c|c|c|c|}
\hline $\begin{array}{l}\text { PULSE SEQUENCE } \\
\text { Relax. delay } 2.000 \text { sec } \\
\text { Pulse } 16.4 \text { degrees } \\
\text { Acq. time } 2.856 \text { sec } \\
\text { Width } 5602.2 \mathrm{~Hz} \\
17 \text { repetitions }\end{array}$ & OBSERVE & $\mathrm{H1}, 400.2688760$ & $\begin{array}{l}\text { DATA PROCESSING } \\
\text { Line broadening } 0.1 \mathrm{~Hz} \\
\text { FT size } 32768 \\
\text { Total time } 1 \mathrm{minute}\end{array}$ \\
\hline
\end{tabular}
Solvent: DMSO

Ambient temperature

Mercury-400 "nmr6" 

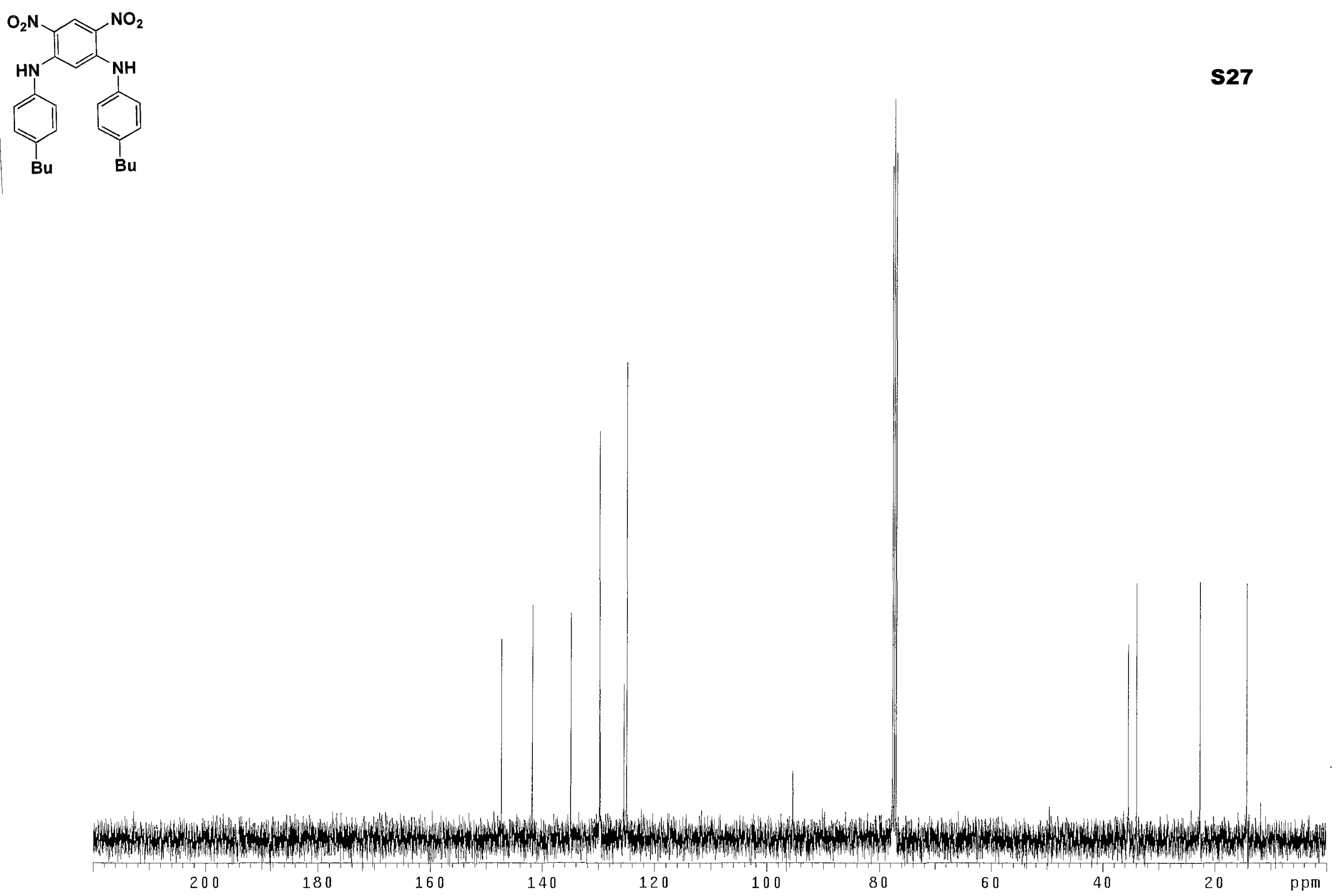

\begin{tabular}{|c|c|c|}
\hline $\begin{array}{l}\text { PULSE SEQUENCE } \\
\text { Relax. delay } 2.000 \mathrm{sec} \\
\text { Pulse } 22.5 \text { degrees } \\
\text { Acq. time } 1.280 \mathrm{sec} \\
\text { width } 25188.9 \mathrm{~Hz} \\
53\end{array}$ & $\begin{array}{l}\text { OBSERVE C13, } 100.6471877 \\
\text { DECOUPLE H1 } \\
\text { POWer } 38 \text { dB } \\
\text { COntinuous ly on } \\
\text { WALTZ-16 modulated }\end{array}$ & $\begin{array}{l}\text { DATA PROCESSING } \\
\text { Line broadening } 1.0 \mathrm{~Hz} \\
\text { FT size } 65536 \\
\text { Total time } 2 \text { minutes }\end{array}$ \\
\hline
\end{tabular}

Pulse Sequence: s2pu Solvent: $\mathrm{CDC} 13$ Ambient temperatur 

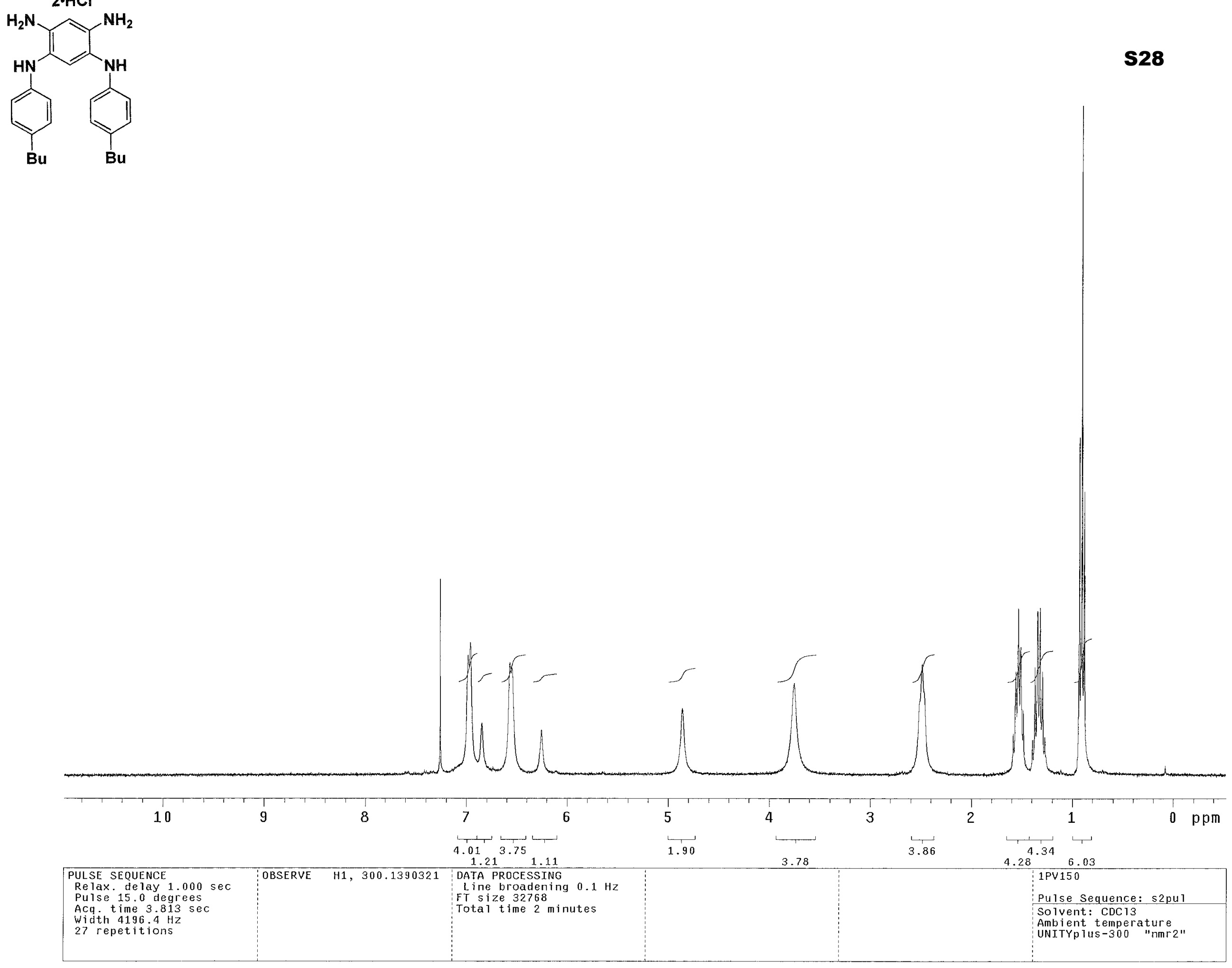


\section{$2 \cdot \mathrm{HCl}$}
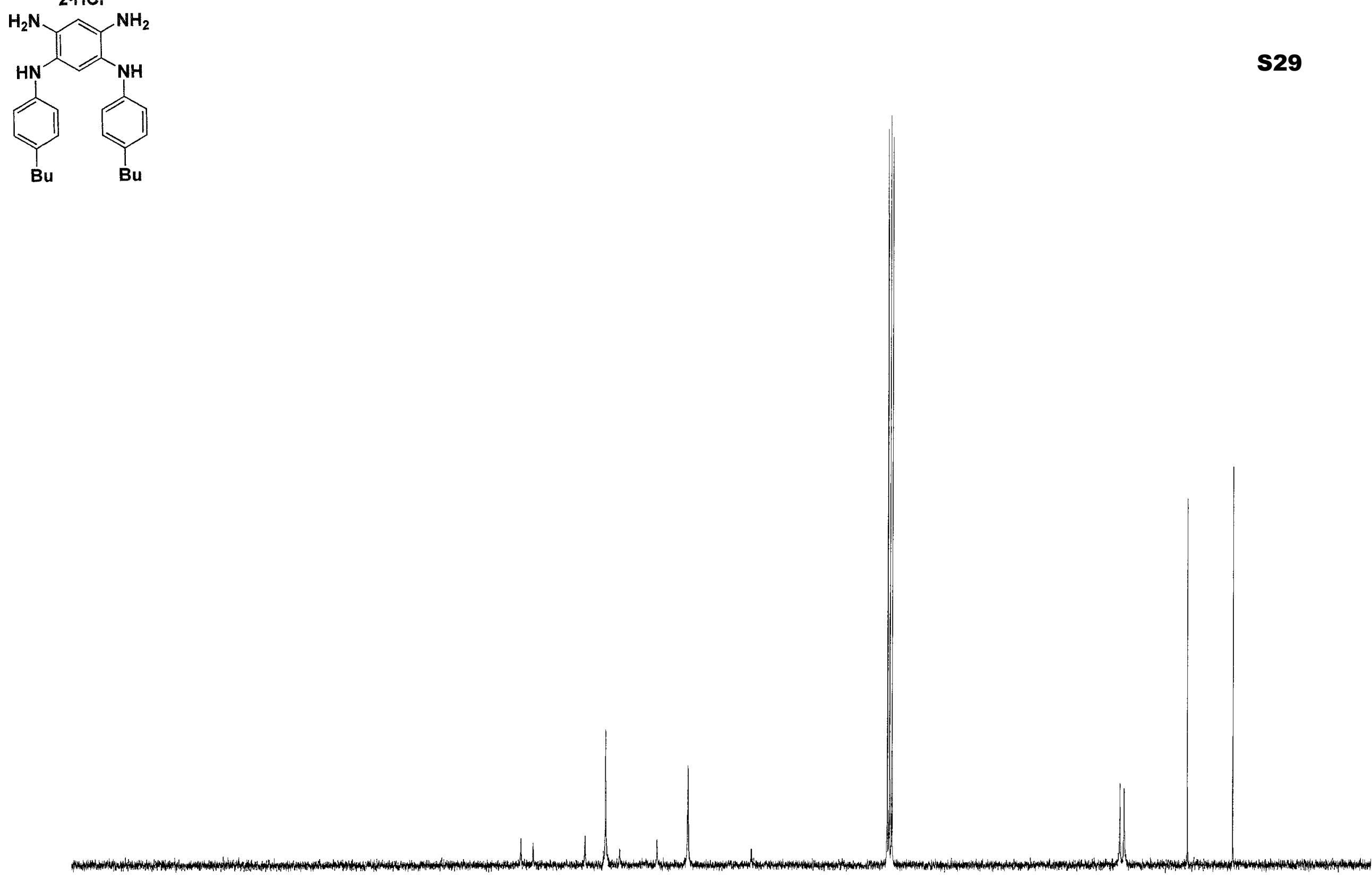

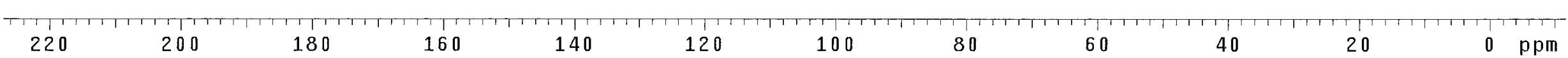

\begin{tabular}{|c|c|c|c|}
\hline $\begin{array}{l}\text { PULSE SEQUENCE } \\
\text { Relax. delay } 2.000 \mathrm{sec} \\
\text { Pulse } 36.0 \text { degrees } \\
\text { Acq. time } 1.777 \mathrm{sec} \\
\text { Width } 18009.9 \mathrm{~Hz} \\
\text { 9175 repetitions }\end{array}$ & $\begin{array}{l}\text { OBSERVE C13, } 75.4700205 \\
\text { DECOUPLE H1, } 300.1409259 \\
\text { Power 40 dB } \\
\text { continuous Iy on } \\
\text { WALTZ-16 modulated } \\
\text { Single precision data }\end{array}$ & $\begin{array}{l}\text { DATA PROCESSING } \\
\text { Line broadening } 1.0 \mathrm{~Hz} \\
\text { FT size } 65536 \\
\text { Total time } 9.6 \text { hours }\end{array}$ & $\begin{array}{l}\text { 1PV50-13C } \\
\text { Pulse sequence: s2pul } \\
\text { Solvent: CDC13 } \\
\text { Ambient temperature } \\
\text { File: BOYDA } \\
\text { UNITYplus-300 "nmr2" }\end{array}$ \\
\hline
\end{tabular}


$2 \cdot \mathrm{HCl}$

OMe

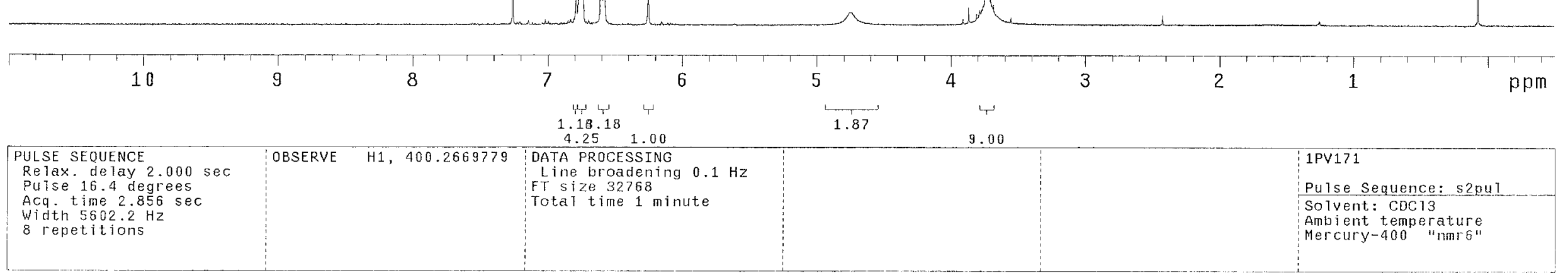




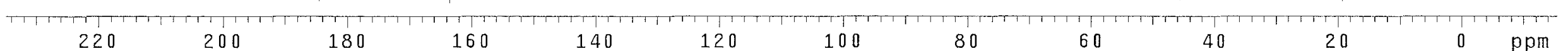

\begin{tabular}{|c|c|c|c|}
\hline $\begin{array}{l}\text { PULSE SEQUENCE } \\
\text { Relax. de7ay 2.000 sec } \\
\text { PuTse } 22.5 \text { degrees } \\
\text { Acq. time } 1.280 \mathrm{sec} \\
\text { Width } 25188.9 \mathrm{~Hz} \\
4035 \text { repetitions }\end{array}$ & $\begin{array}{l}\text { OBSERVE C13, } 100.6472130 \\
\text { DECOUPLE H1, } 400.2689955 \\
\text { POWer } 38 \text { dB } \\
\text { COntinuously on } \\
\text { WALTZ-16 modulated }\end{array}$ & $\begin{array}{l}\text { DATA PROCESSING } \\
\text { Line broadening } 1.0 \mathrm{~Hz} \\
\text { FT size } 65536 \\
\text { Total time } 3.7 \text { hours }\end{array}$ & $\begin{array}{l}\text { 1PV171-13C } \\
\text { PuTse sequence: s2pur } \\
\text { SoTvent: CDCi3 } \\
\text { Ambient temperature } \\
\text { Mercury-400 "mimrs" }\end{array}$ \\
\hline
\end{tabular}




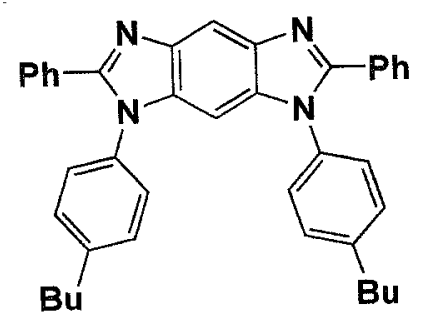

533

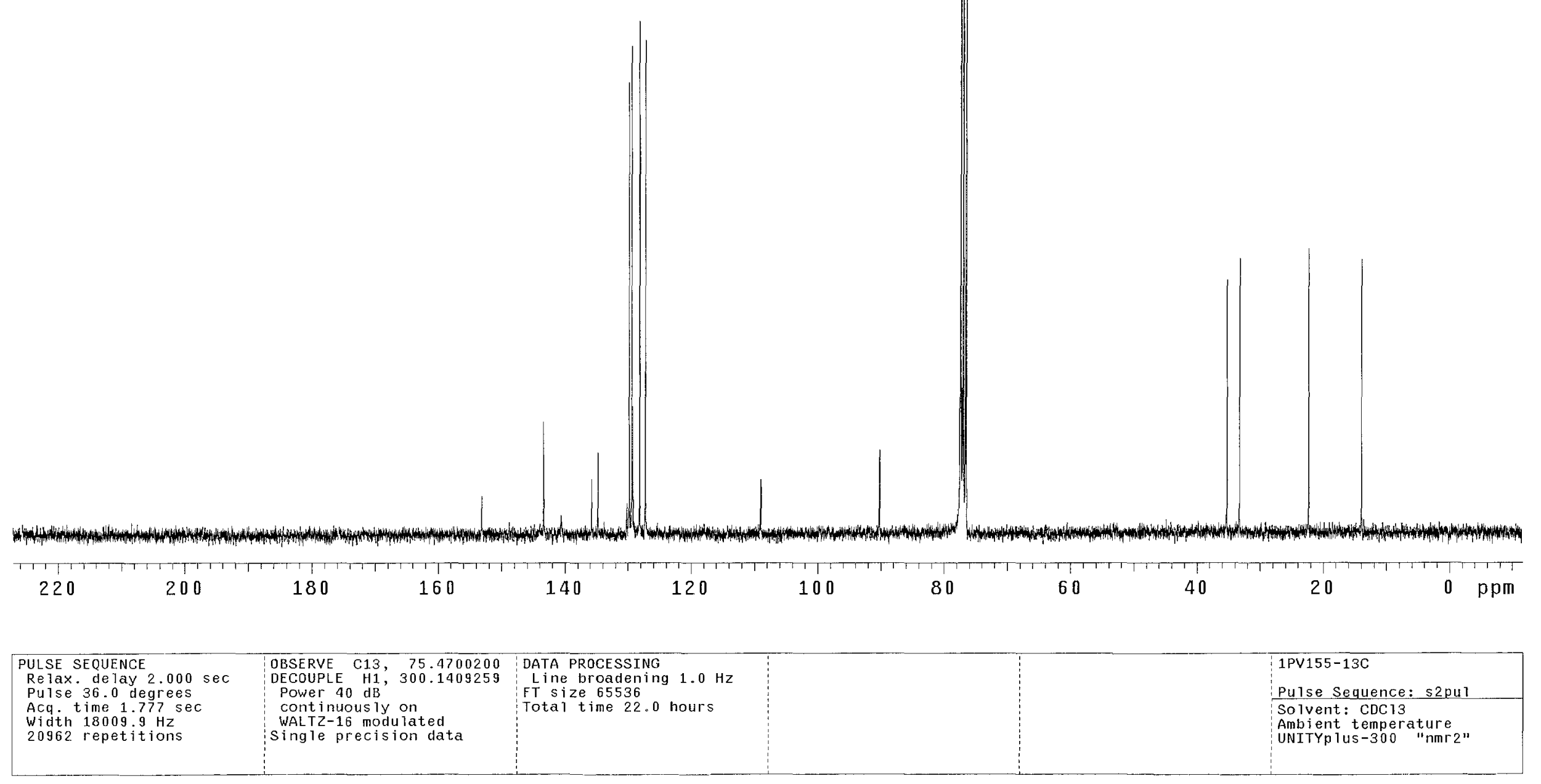




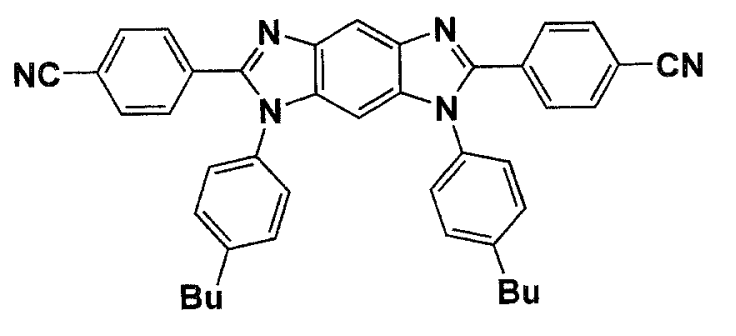

534

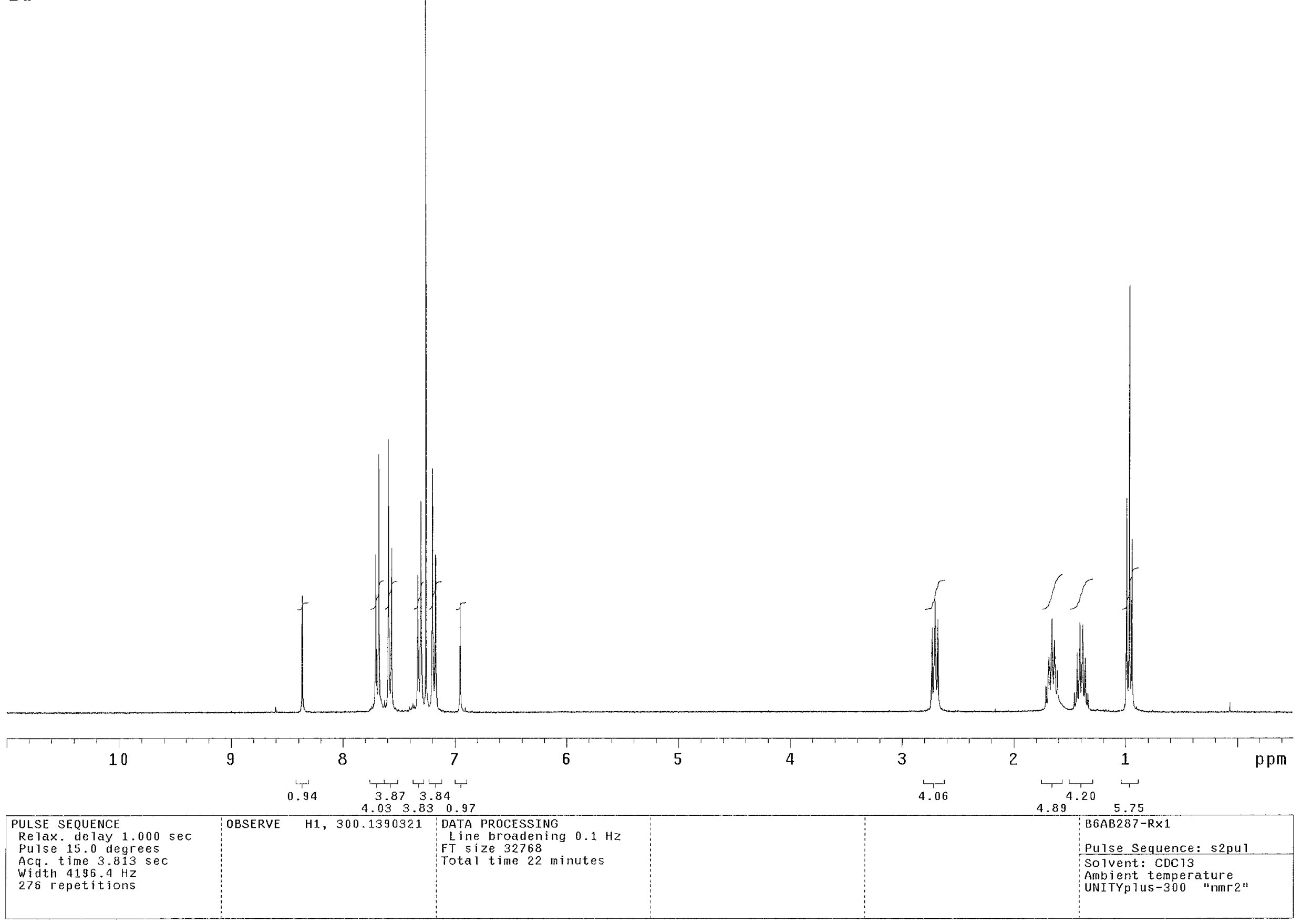




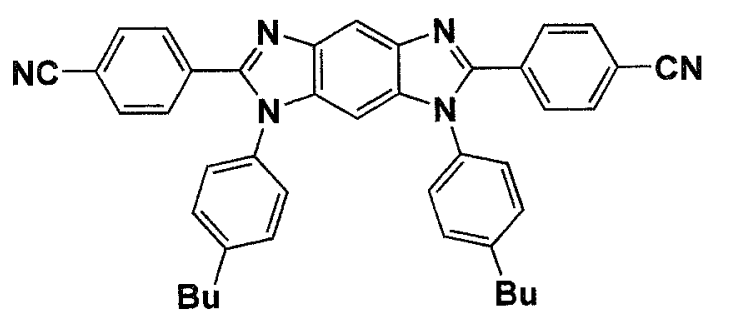

$\mathbf{S 3 5}$

1.t.

\begin{tabular}{|c|c|c|c|c|c|}
\hline $220 \quad 200$ & $\begin{array}{l}11 \\
180\end{array}$ & 120 & $100 \quad 80$ & $60 \quad 40$ & $\begin{array}{ccc}1 & & \\
20 & 0 & p p m\end{array}$ \\
\hline $\begin{array}{l}\text { PULSE SEQUENCE } \\
\text { Relax. de } 1 \text { ay } 2.000 \text { sec } \\
\text { Pulse } 36.0 \text { degrees } \\
\text { Acq. time } 1.777 \text { sec } \\
\text { Width } 18009 \text { d Hz } \\
\text { 9232 repetitions }\end{array}$ & $\begin{array}{l}\text { OBSERVE C13, } 75.4700200 \\
\text { DECOUPLE H1, } 300.1409259 \\
\text { POwer } 40 \text { dB } \\
\text { cont inuous 1y on } \\
\text { wALTZ-16 modulated } \\
\text { Single precision data }\end{array}$ & $\begin{array}{l}\text { DATA PROCESSING } \\
\text { Line broadening } 1.0 \mathrm{~Hz} \\
\text { FT size } 65536 \\
\text { Total time } 9.7 \text { hours }\end{array}$ & & & $\begin{array}{l}\text { B6AB287-13C } \\
\text { Pu1se Sequence: s2pu1 } \\
\text { Solvent: CDC13 } \\
\text { Ambient temperature } \\
\text { UNITYplus-300 "nmr2" }\end{array}$ \\
\hline
\end{tabular}



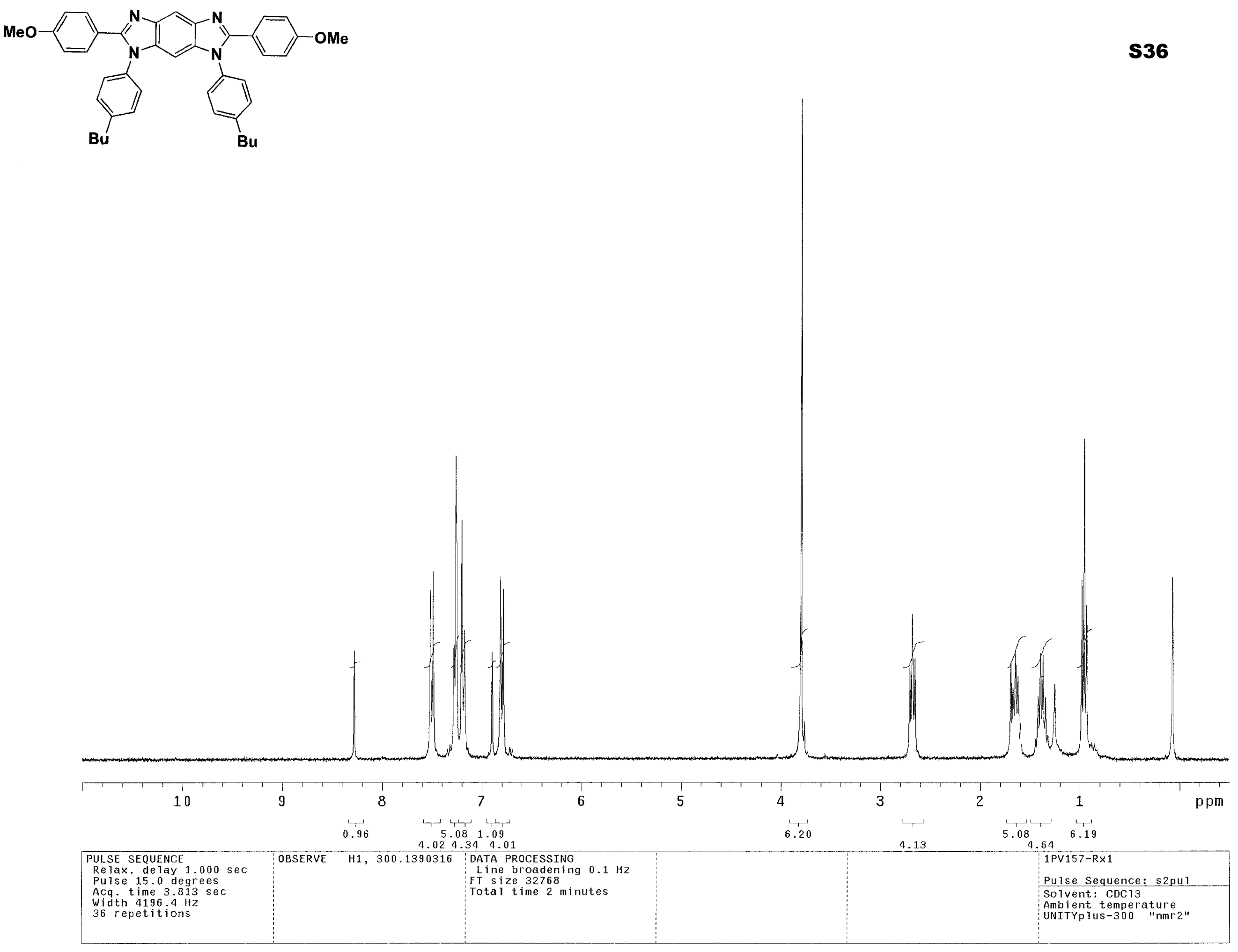

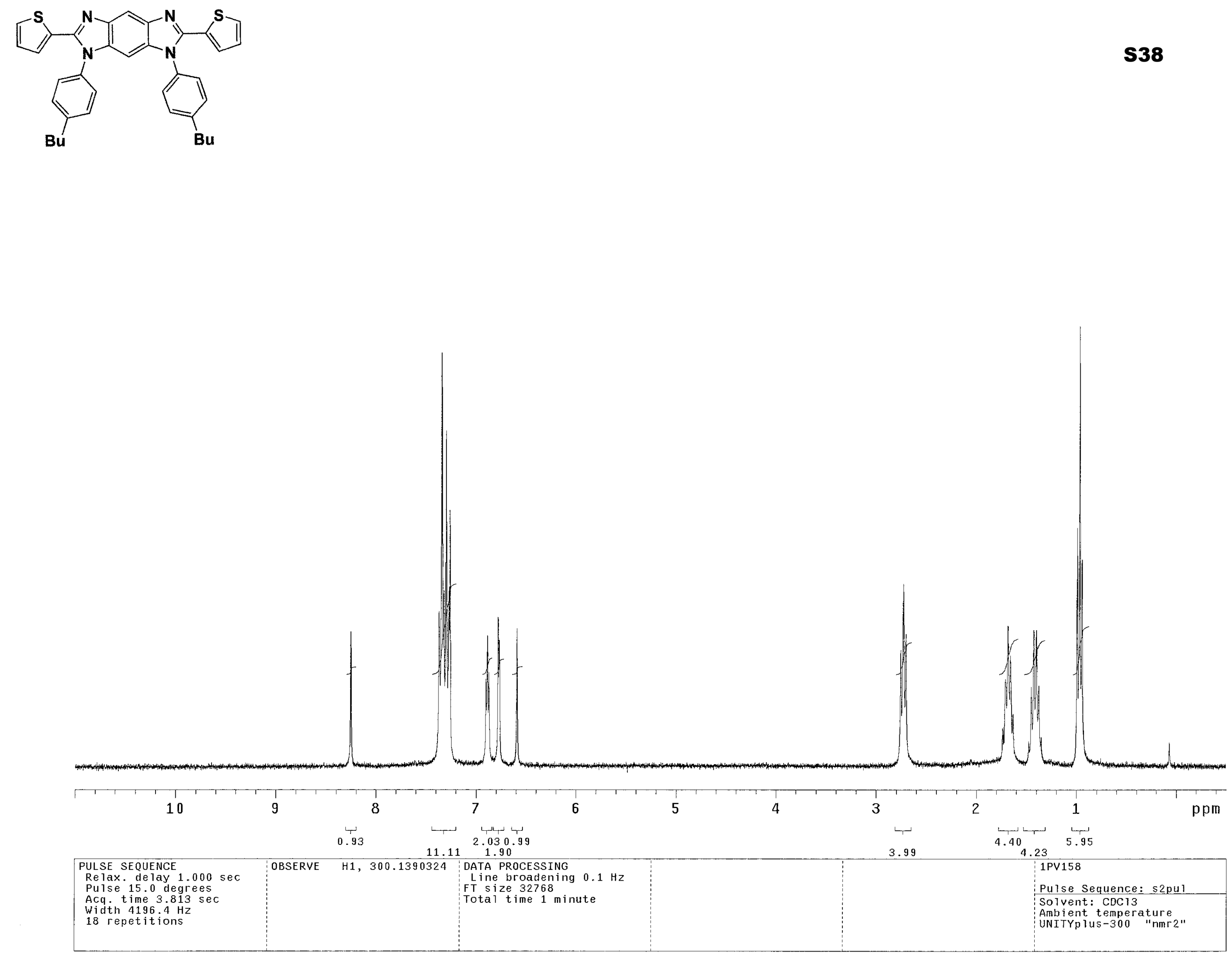


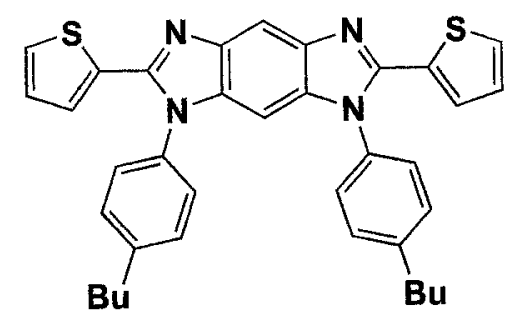

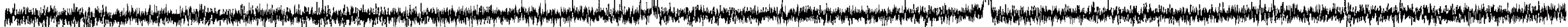

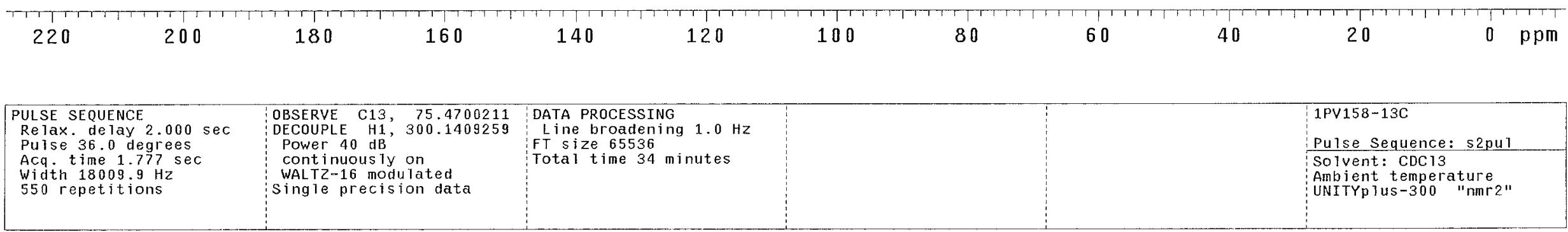



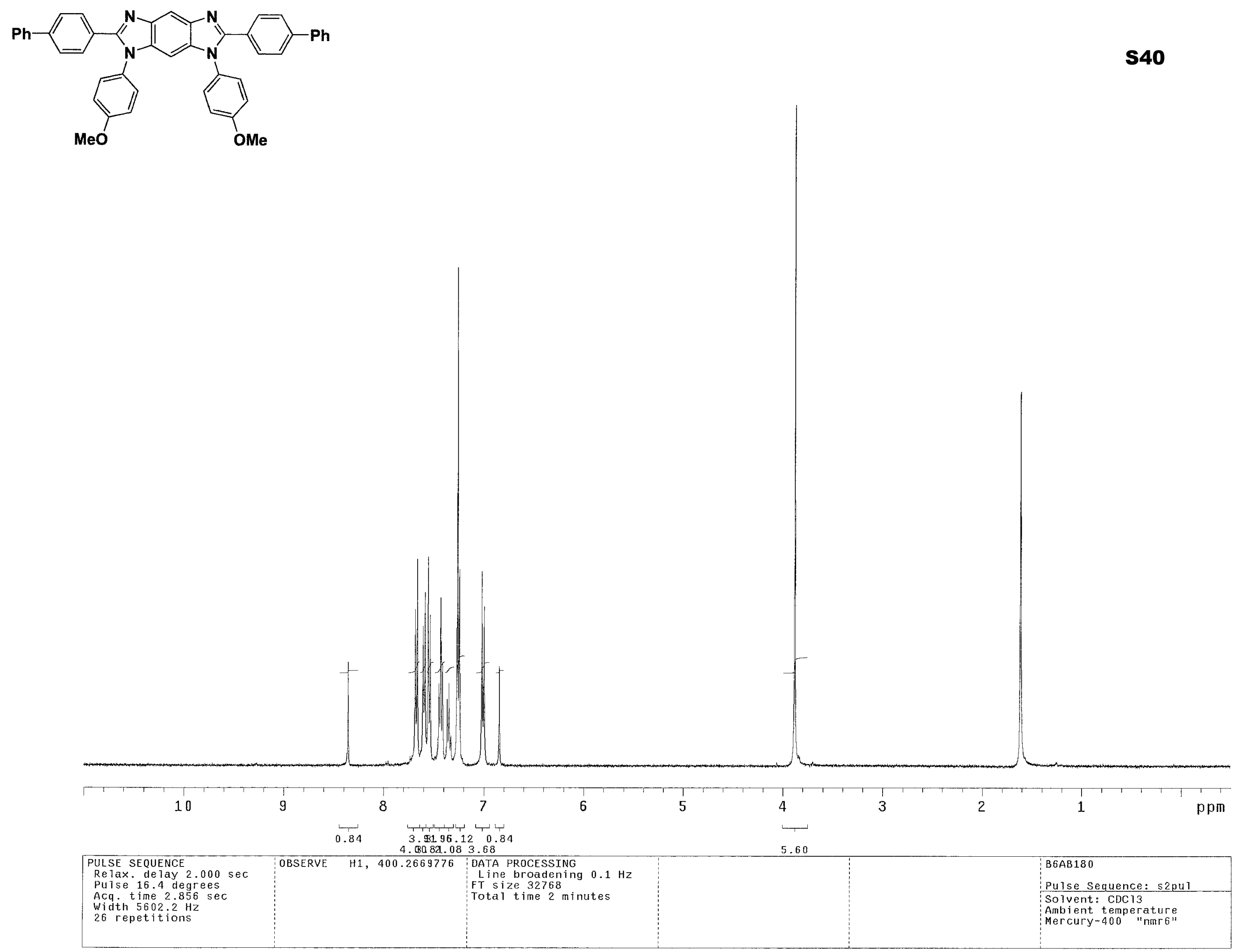


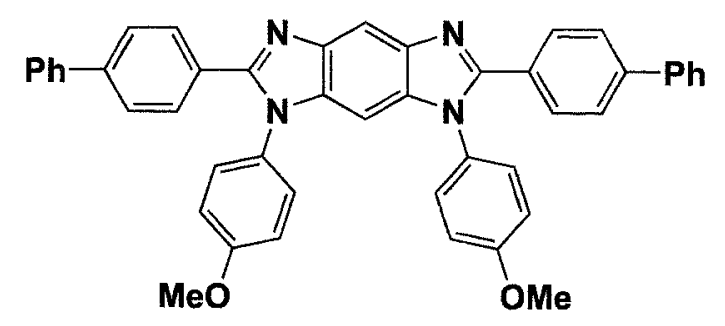

How

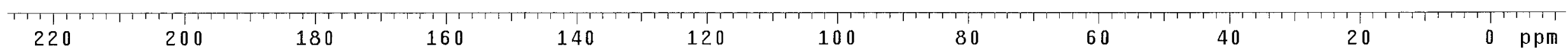

\begin{tabular}{|c|c|c|c|}
\hline $\begin{array}{l}\text { PULSE SEQUENCE } \\
\text { Relax. delay } 2.000 \mathrm{sec} \\
\text { Pulse } 36.0 \text { degrees } \\
\text { ACq time } 1.777 \mathrm{sec} \\
\text { Width } 18009.9 \mathrm{~Hz} \\
1353 \text { repetitions }\end{array}$ & $\begin{array}{l}\text { OBSERVE C13, } 75.4700200 \\
\text { DECOUPLE H1, } 300.1409259 \\
\text { POWer 40 dB } \\
\text { COnt inuous ly on } \\
\text { WALTZ-16 modulated } \\
\text { single precision data }\end{array}$ & $\begin{array}{l}\text { DATA PROCESSING } \\
\text { Line broadening } 1.0 \mathrm{~Hz} \\
\text { size } 65536 \\
\text { Total time } 85 \text { minutes }\end{array}$ & $\begin{array}{l}\text { B6AB180-13C } \\
\text { Pulse sequence: s2pul } \\
\text { Solvent: CDC13 } \\
\text { Ambient temperature } \\
\text { UNITYp Ius }-300 \text { "nmr2" }\end{array}$ \\
\hline
\end{tabular}



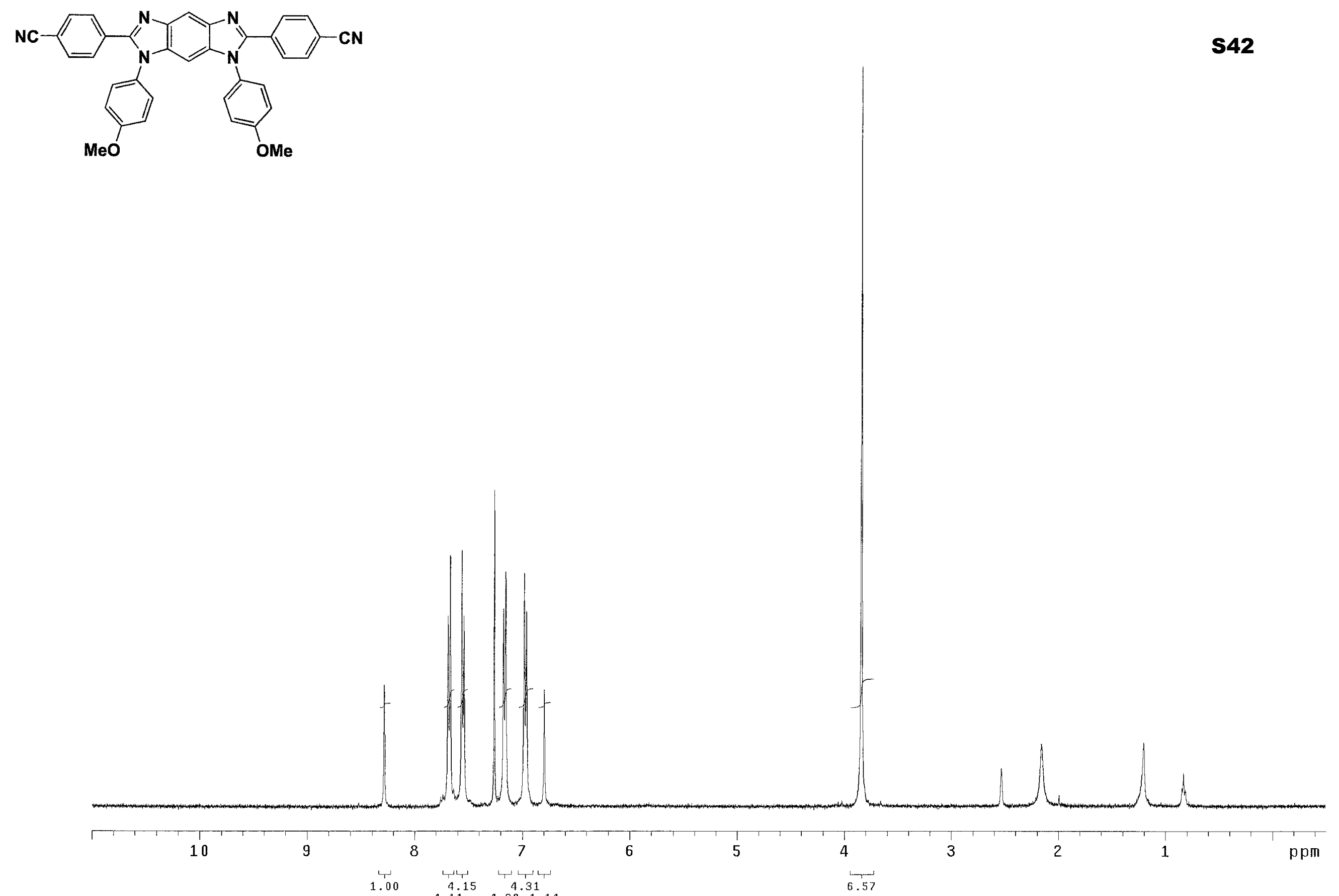

Acq in $5602.25 \mathrm{~s}$

13 repetitions

OBSERVE H1, 400.2669776 DATA PROCESSING

Line broadening $0.1 \mathrm{~Hz}$

Total time 1 minute 

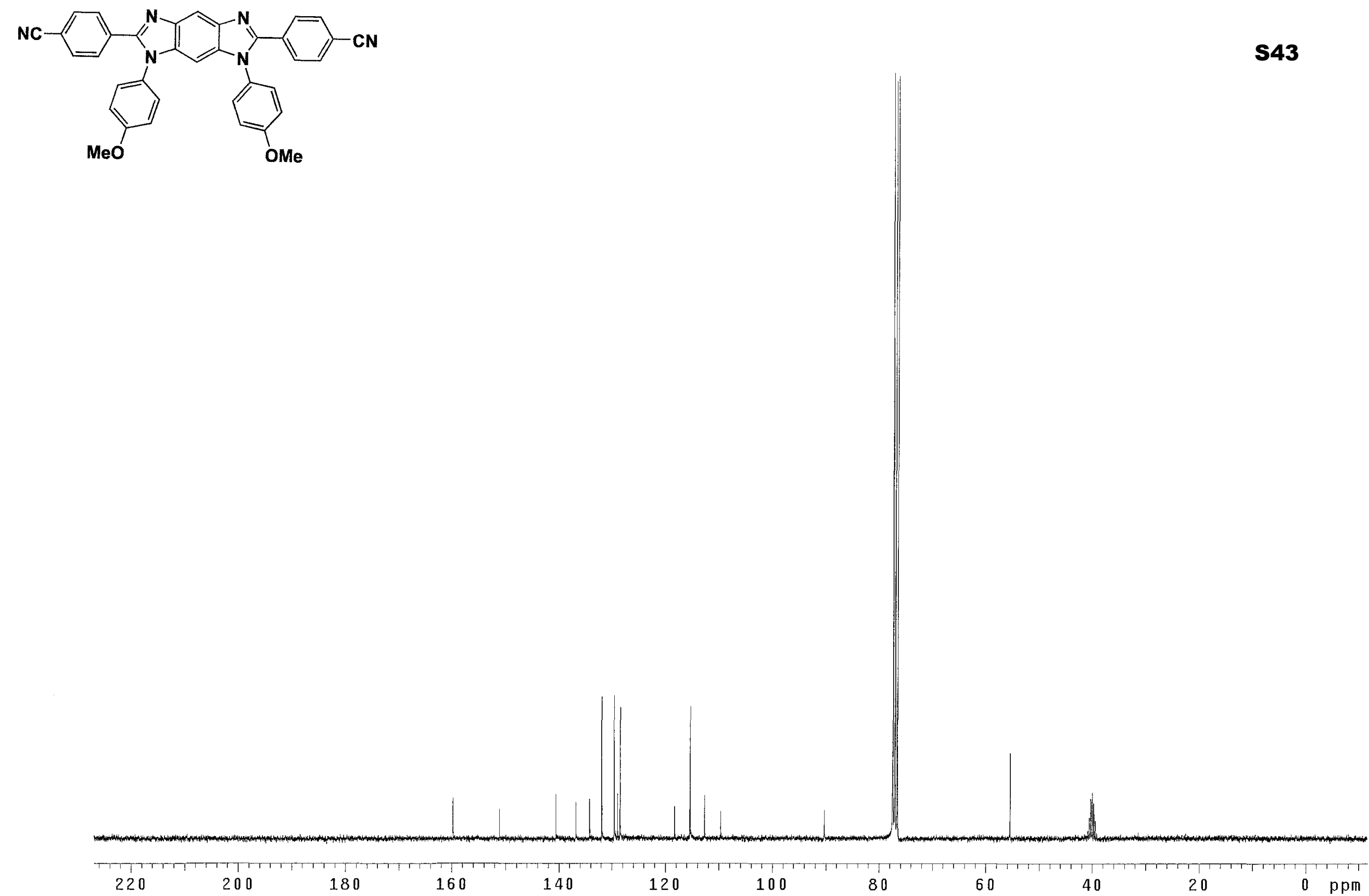


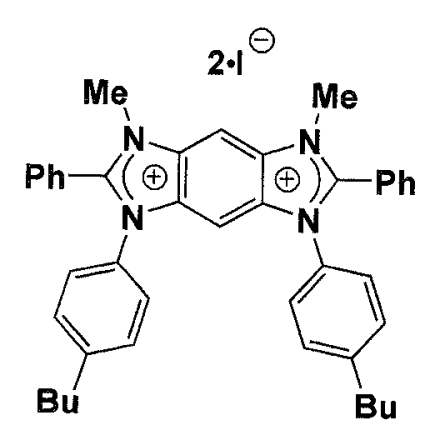

\section{5}

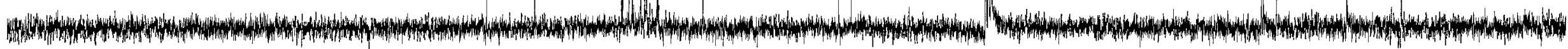

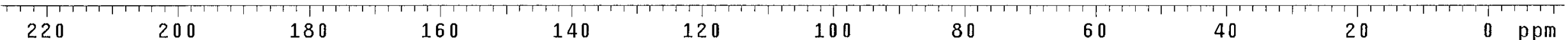

\begin{tabular}{|c|c|c|}
\hline $\begin{array}{l}\text { PULSE SEQUENCE } \\
\text { Relax. delay } 2.000 \mathrm{sec} \\
\text { Pulse } 36.0 \mathrm{degrees} \\
\text { ACq. time } 1.777 \mathrm{sec} \\
\text { Width } 18009.9 \mathrm{~Hz} \\
544 \text { repetitions }\end{array}$ & $\begin{array}{l}\text { OBSERVE C13, } 75.4700238 \\
\text { DECOUPLE H1', } 300.1409259 \\
\text { Power 40 dB } \\
\text { cont } 1 \text { nuous Iy on } \\
\text { WALTZ-16 modulated } \\
\text { single precision data }\end{array}$ & $\begin{array}{l}\text { DATA PROCESSING } \\
\text { Line broadening } 1.0 \mathrm{~Hz} \\
\text { FT size } 65536 \\
\text { Total time } 34 \text { minutes }\end{array}$ \\
\hline
\end{tabular}



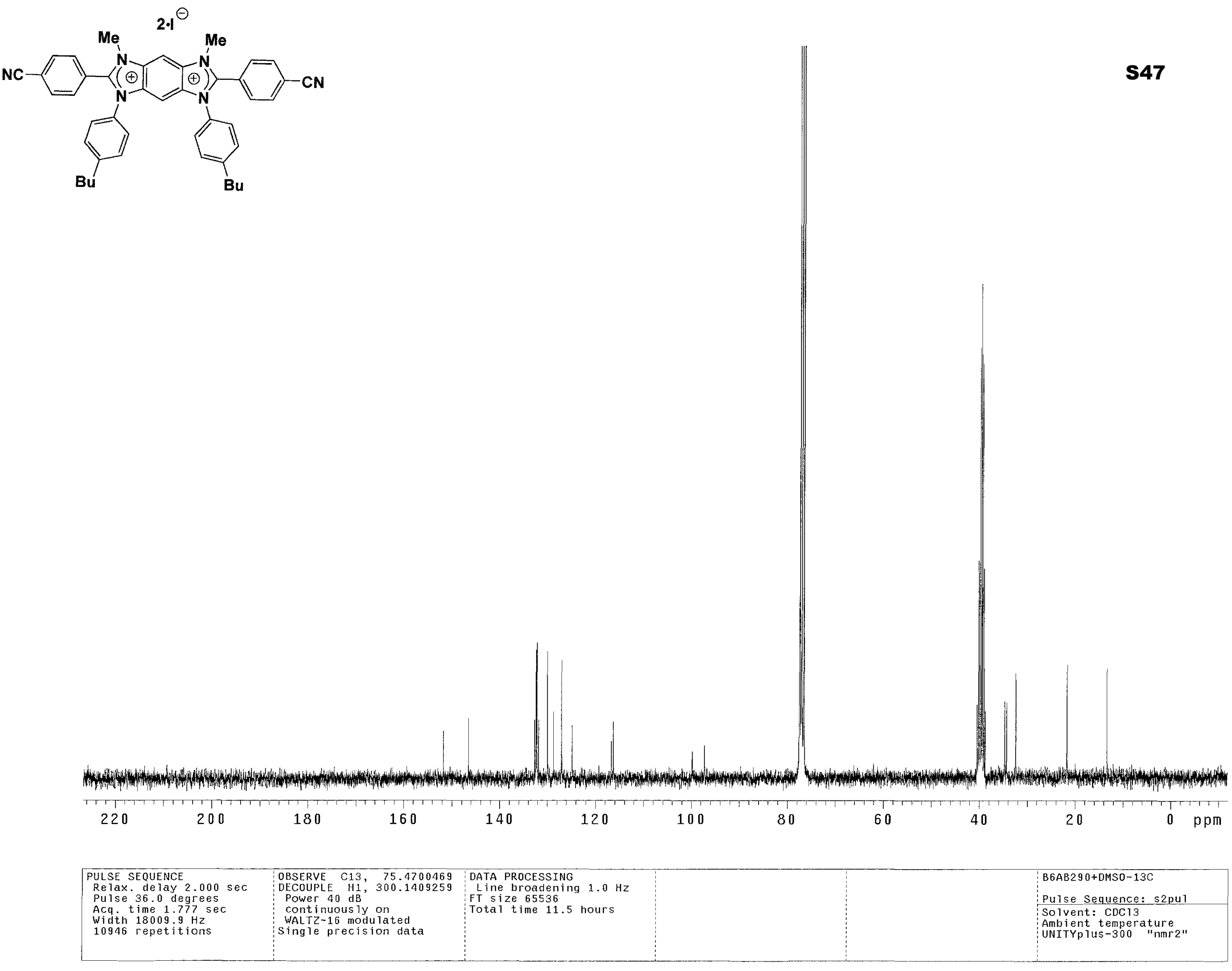


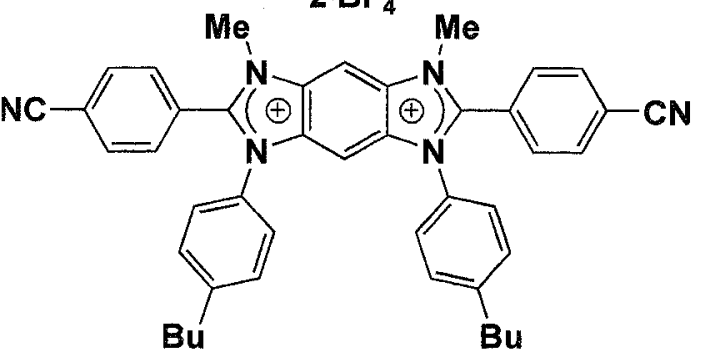

549

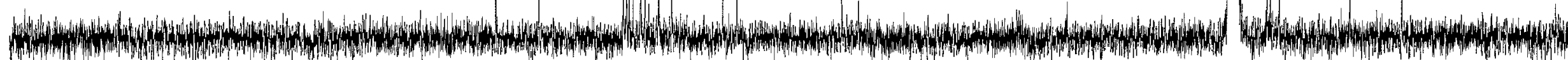

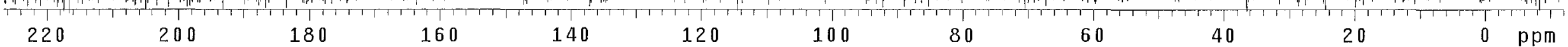

\begin{tabular}{|c|c|c|}
\hline $\begin{array}{l}\text { PULSE SEQUENCE } \\
\text { Relax. de lay } 2.000 \mathrm{sec} \\
\text { Pulse } 36.0 \text { degrees } \\
\text { Acq. time } 1.77 \text { sec } \\
\text { Width } 18009 \text { Hz } \\
2327 \text { repetitions }\end{array}$ & $\begin{array}{l}\text { OBSERVE C13, } 75.4704126 \\
\text { DECOUPLE H1, } 300.1423516 \\
\text { Power 40 dB } \\
\text { Cont inuous ly on } \\
\text { WALTZ-16 modulated } \\
\text { Single precision data }\end{array}$ & $\begin{array}{l}\text { DATA PROCESSING } \\
\text { Line broadening } 1.0 \mathrm{~Hz} \\
\text { FT size } 65536 \\
\text { Total time } 2.4 \text { hours }\end{array}$ \\
\hline
\end{tabular}

B6AB299-13C

Pulse Sequence: s2pur

Solvent: DMSO

Ambient temperature 

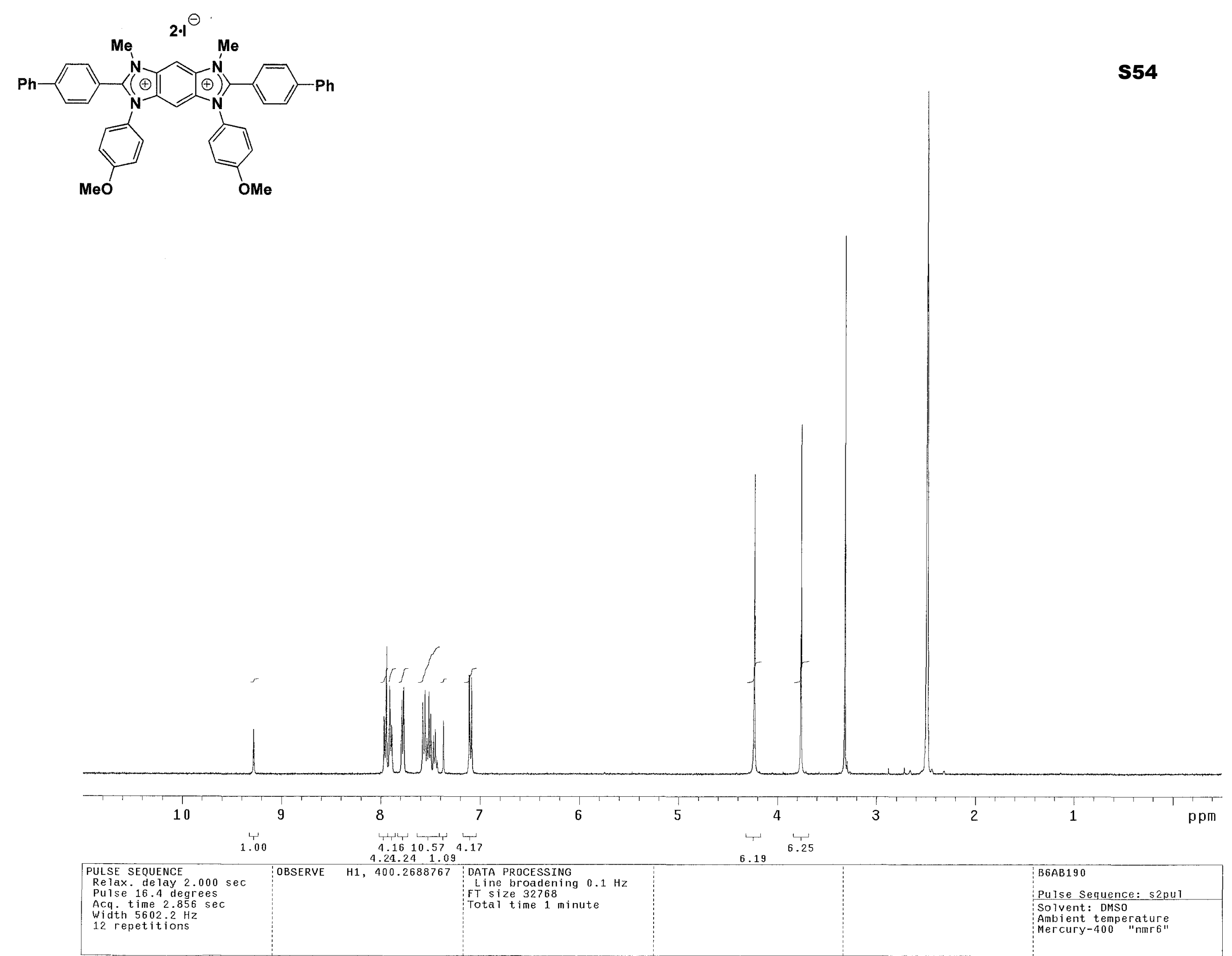

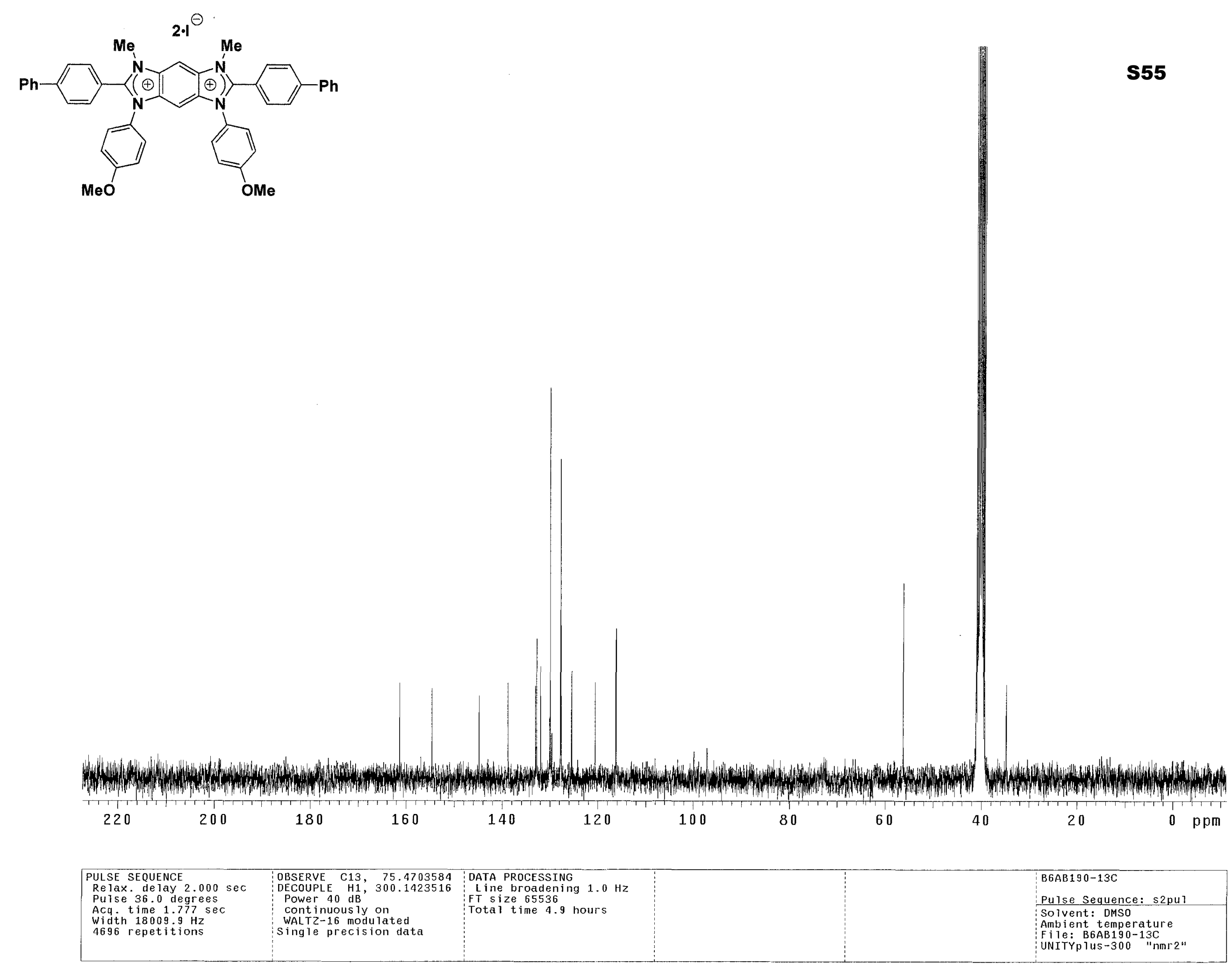

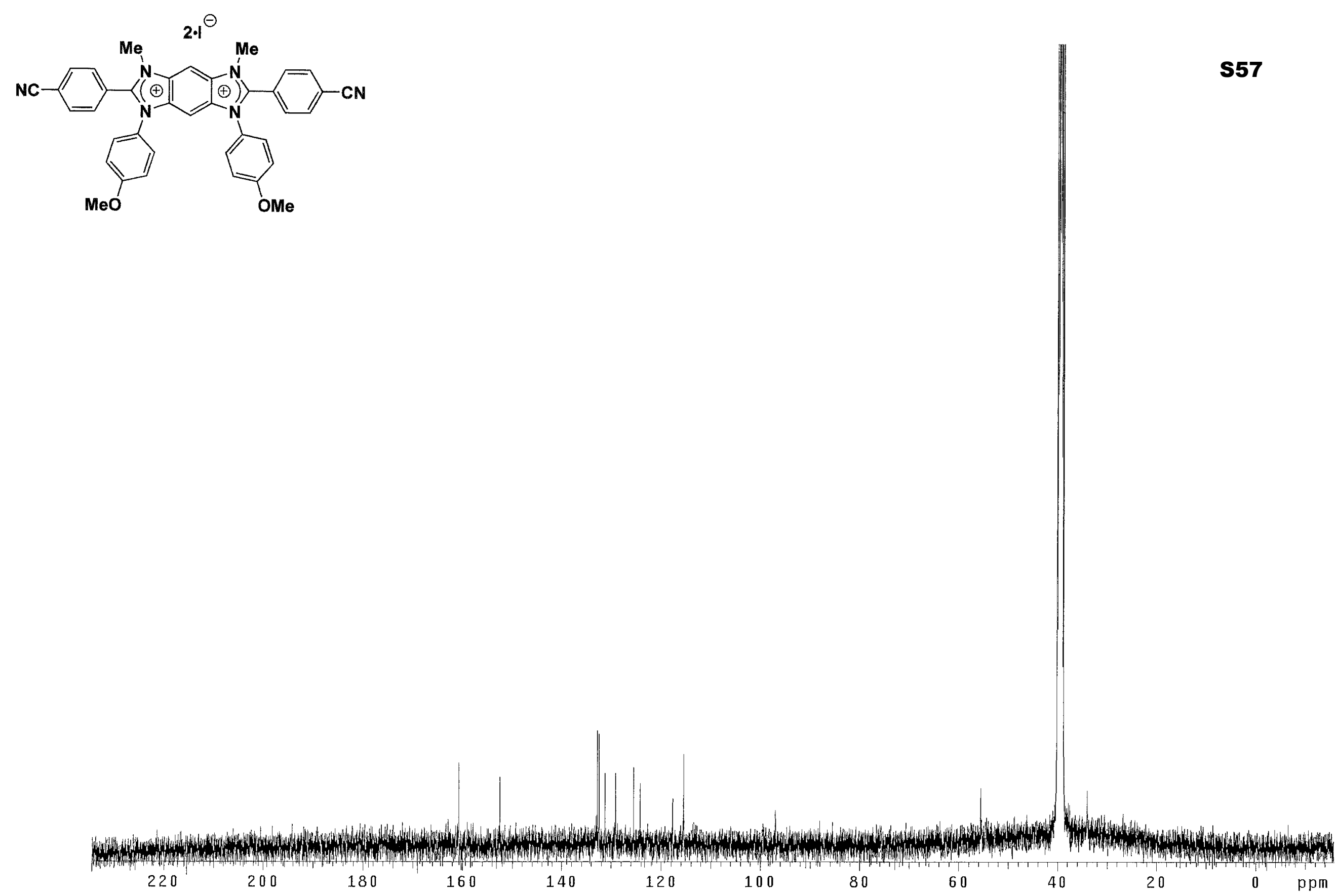

\begin{tabular}{|c|c|c|c|}
\hline $\begin{array}{l}\text { PULSE SEQUENCE } \\
\text { Relax. delay } 2.000 \mathrm{sec} \\
\text { Pulse } 22.5 \mathrm{degrees} \\
\text { Acr. time } 1.280 \mathrm{sec} \\
\text { Width } 25188.9 \mathrm{~Hz} \\
11398 \text { repetitions }\end{array}$ & $\begin{array}{l}\text { OBSERVE C13, } 100.6477357 \\
\text { DECOUPLE H1, } 400.2708968 \\
\text { POWer } 38 \text { dB } \\
\text { cont inuous 1Y on } \\
\text { WALTZ-16 modulated }\end{array}$ & $\begin{array}{l}\text { DATA PROCESSING } \\
\text { Line broadening } 1.0 \mathrm{~Hz} \\
\text { FT size } 65536 \\
\text { Total time } 10.4 \text { hours }\end{array}$ & $\begin{array}{l}\text { BGAB191-13C } \\
\text { Pulse sequence: s2pul } \\
\text { Solvent: DMSO } \\
\text { Ambient temperature } \\
\text { Mercury-400 "nmr6" }\end{array}$ \\
\hline
\end{tabular}




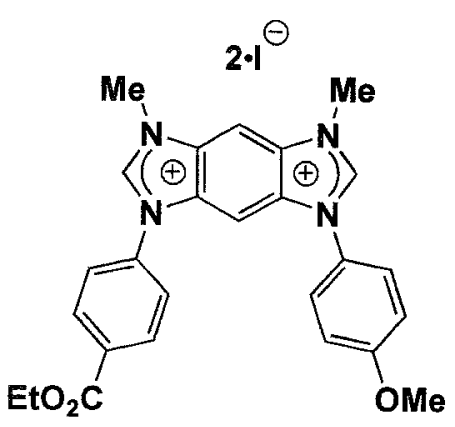

\begin{tabular}{|c|c|c|}
\hline $\begin{array}{l}\text { PULSE SEQUENCE } \\
\text { Relax. delay } 2.000 \mathrm{sec} \\
\text { Pulse } 22.5 \text { degrees } \\
\text { Acq. time } 1.280 \mathrm{sec} \\
\text { Width } 25188.9 \mathrm{~Hz} \\
3408 \text { repetitions }\end{array}$ & $\begin{array}{l}\text { OBSERVE C13, } 100.6477364 \\
\text { DECOUPLE H1, } 400.2708968 \\
\text { Power } 38 \text { dB } \\
\text { COnt inuous } 7 y \text { on } \\
\text { WALTZ-16 modulated }\end{array}$ & $\begin{array}{l}\text { DATA PROCESSING } \\
\text { Line broadening } 1.0 \mathrm{~Hz} \\
\text { FT size } 65536 \\
\text { Totat time } 3.1 \text { hours }\end{array}$ \\
\hline
\end{tabular}



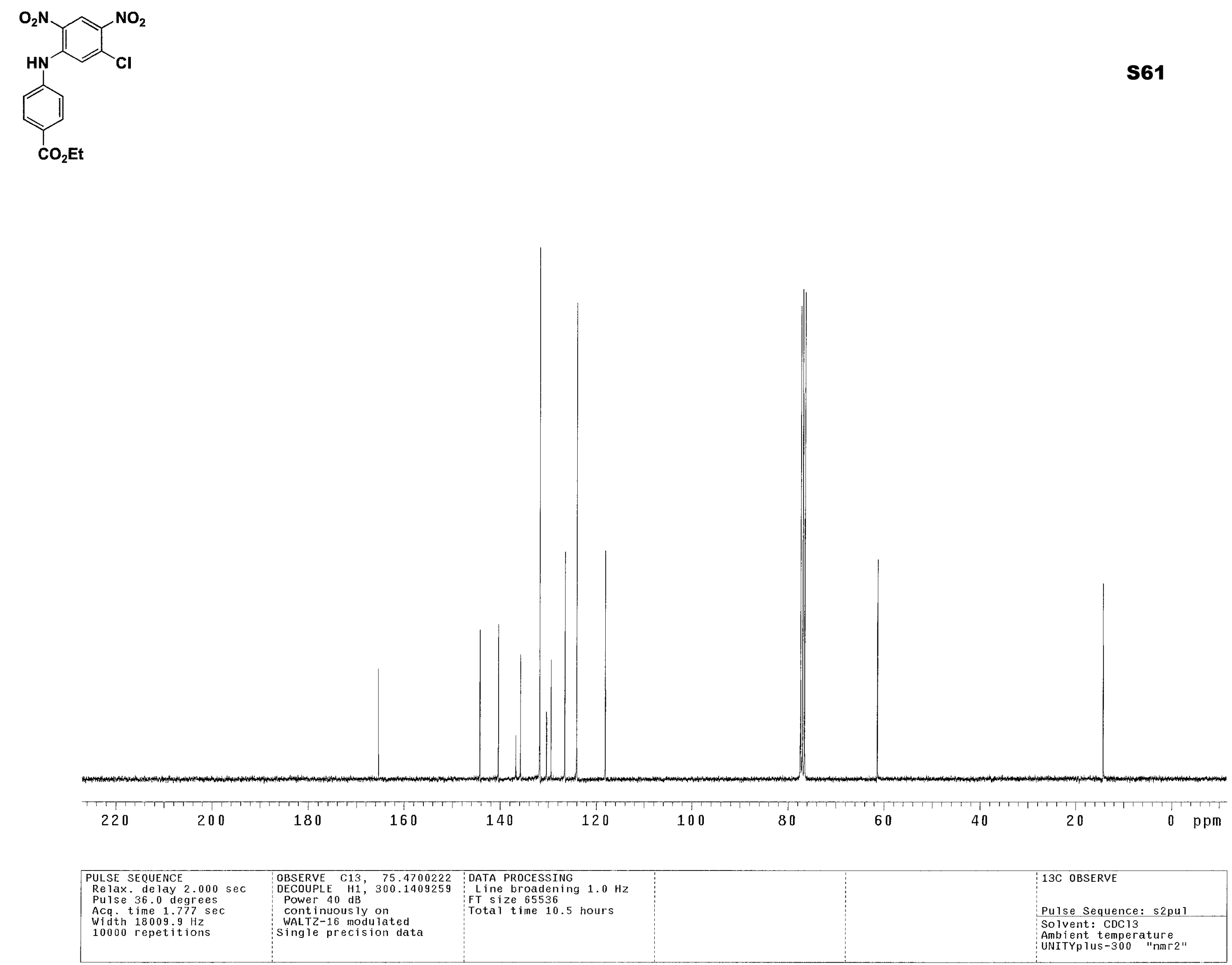

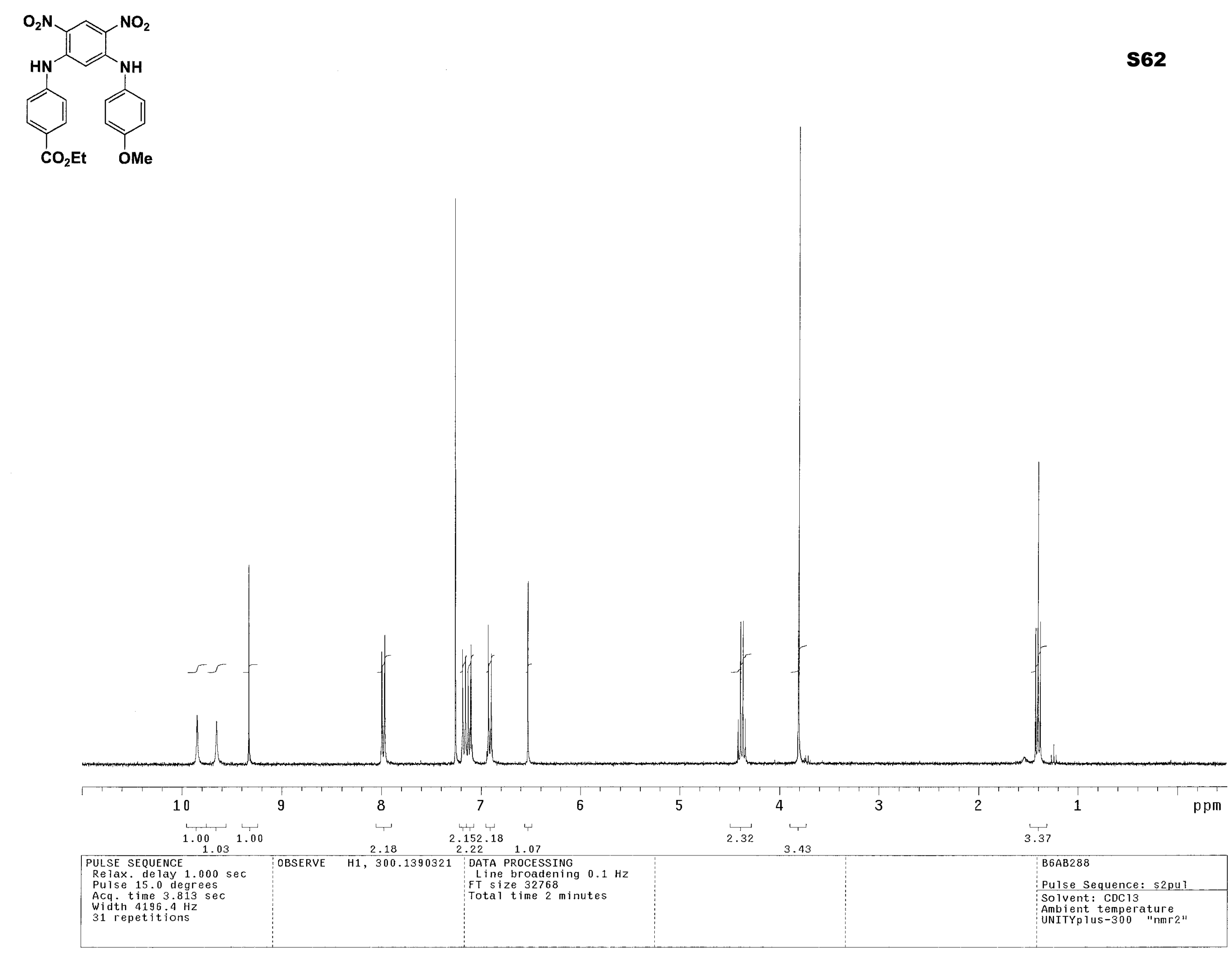

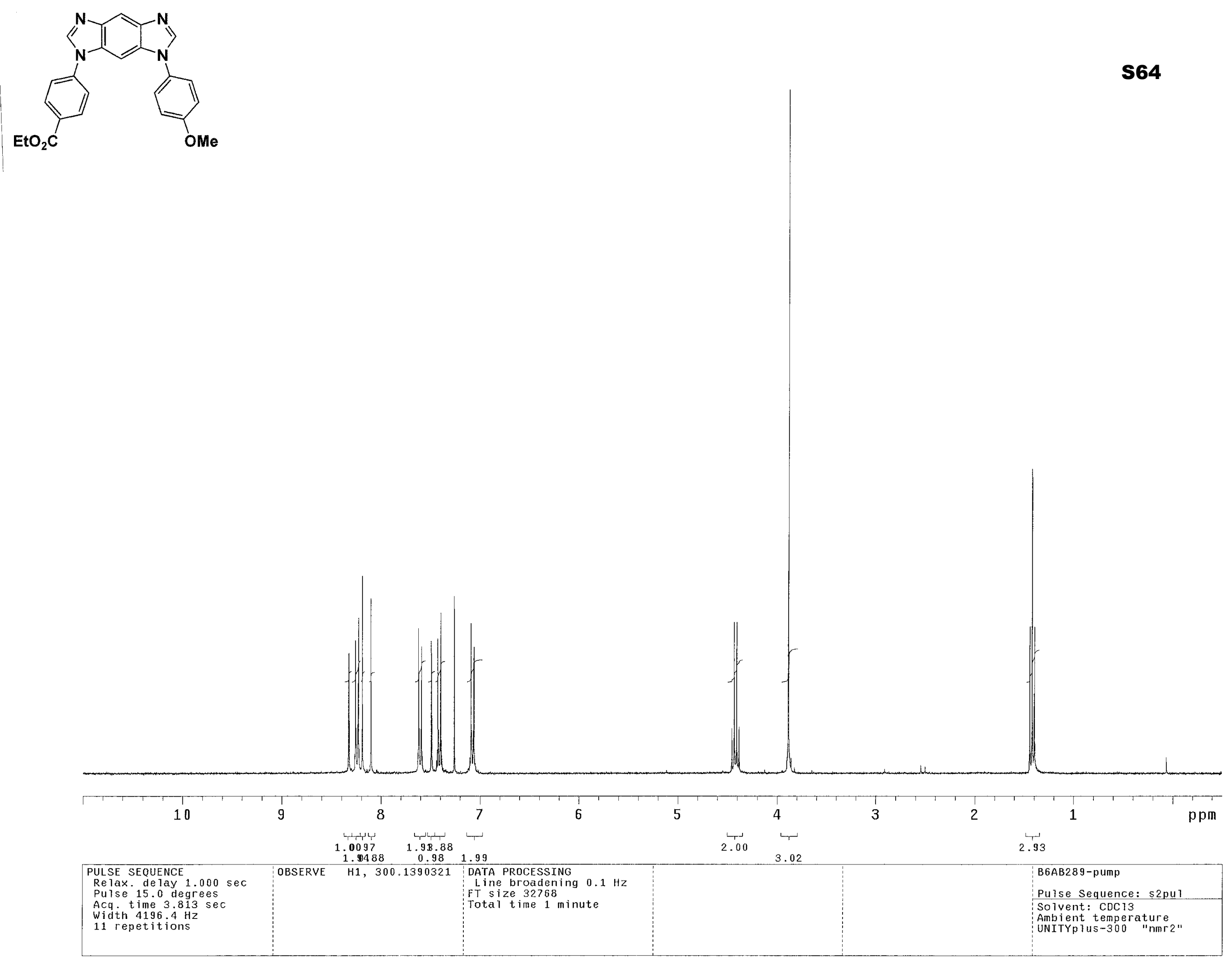

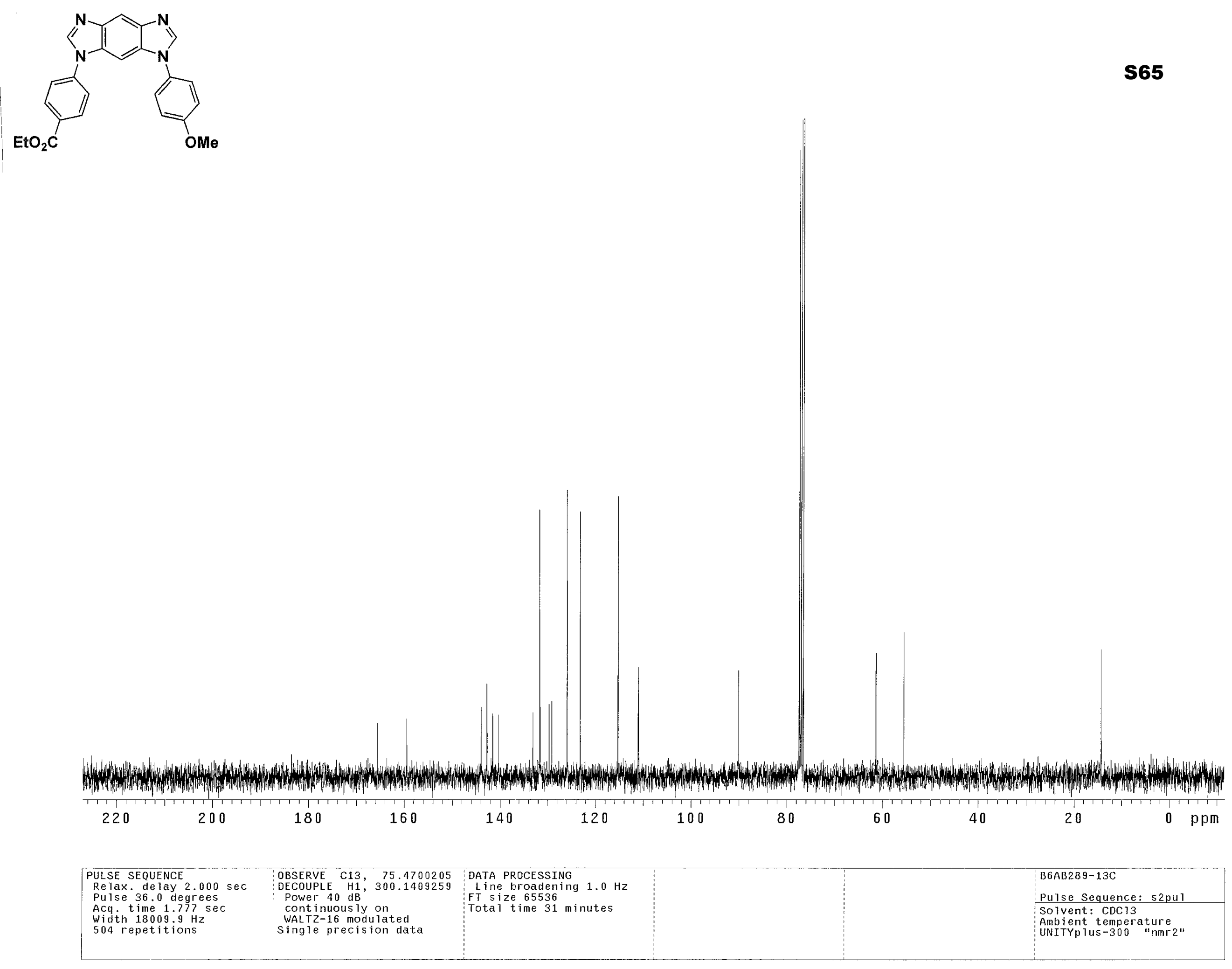


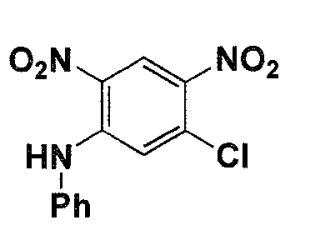

566

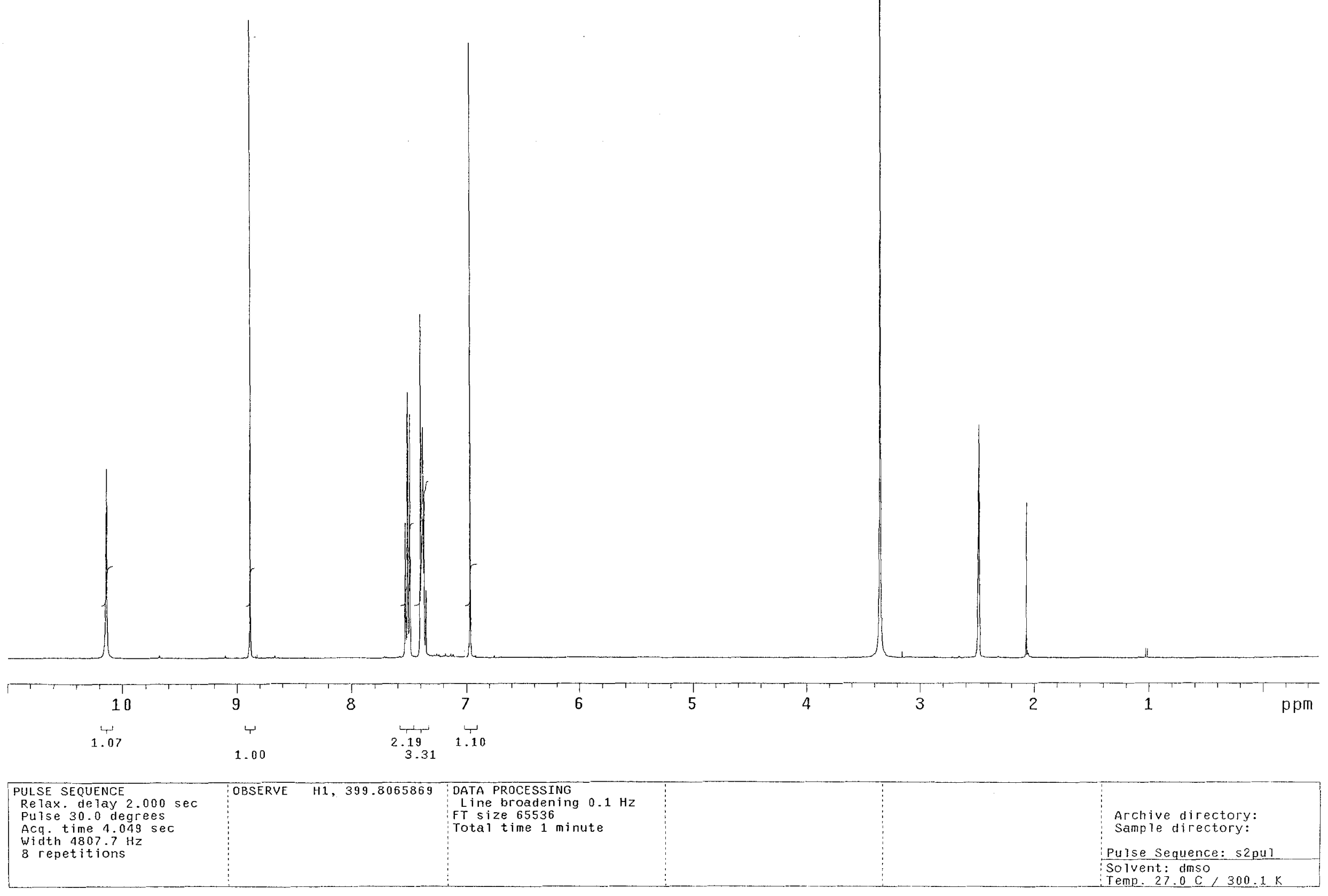



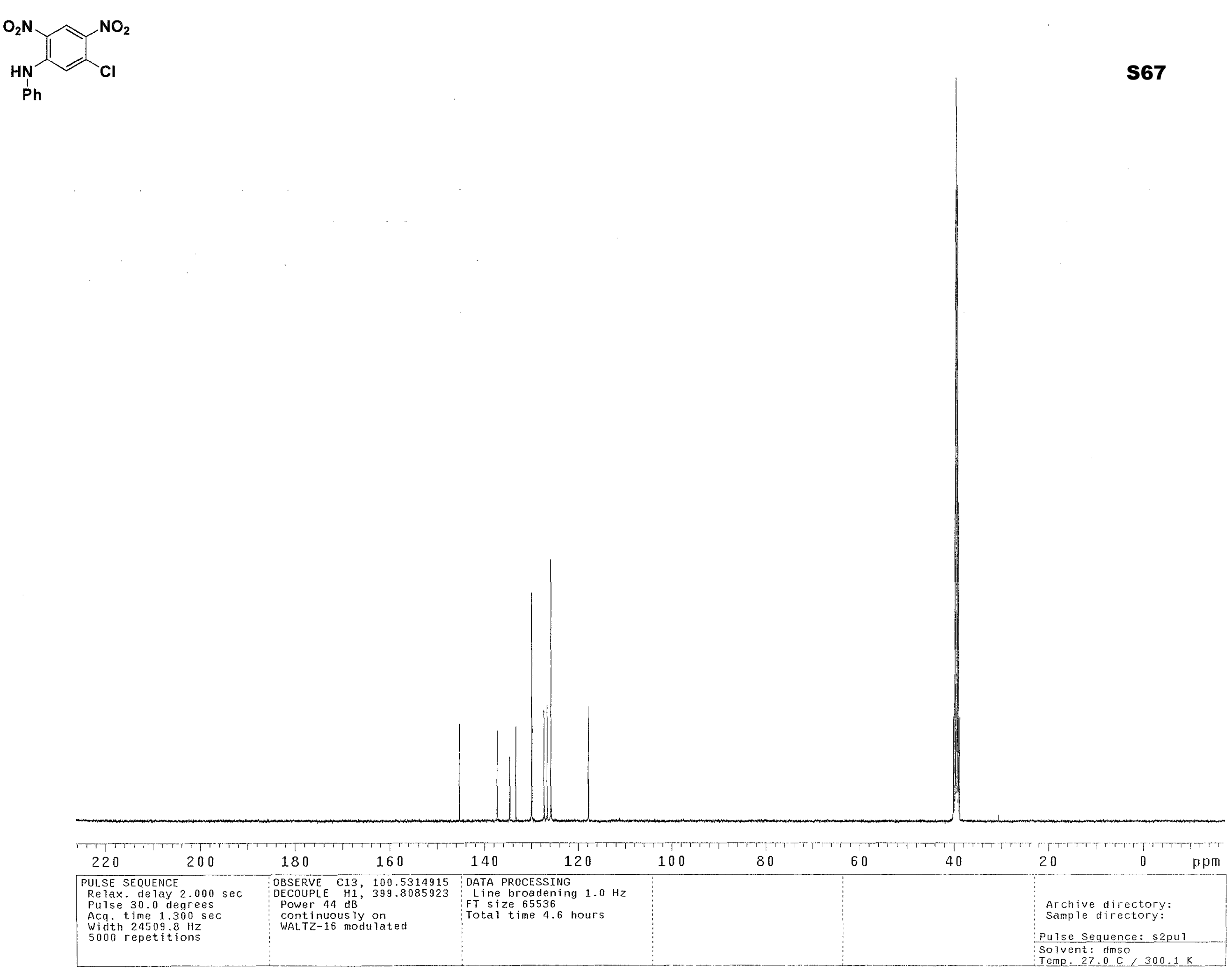


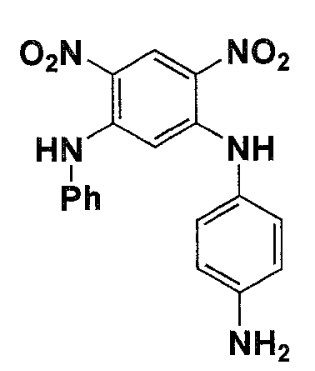

568

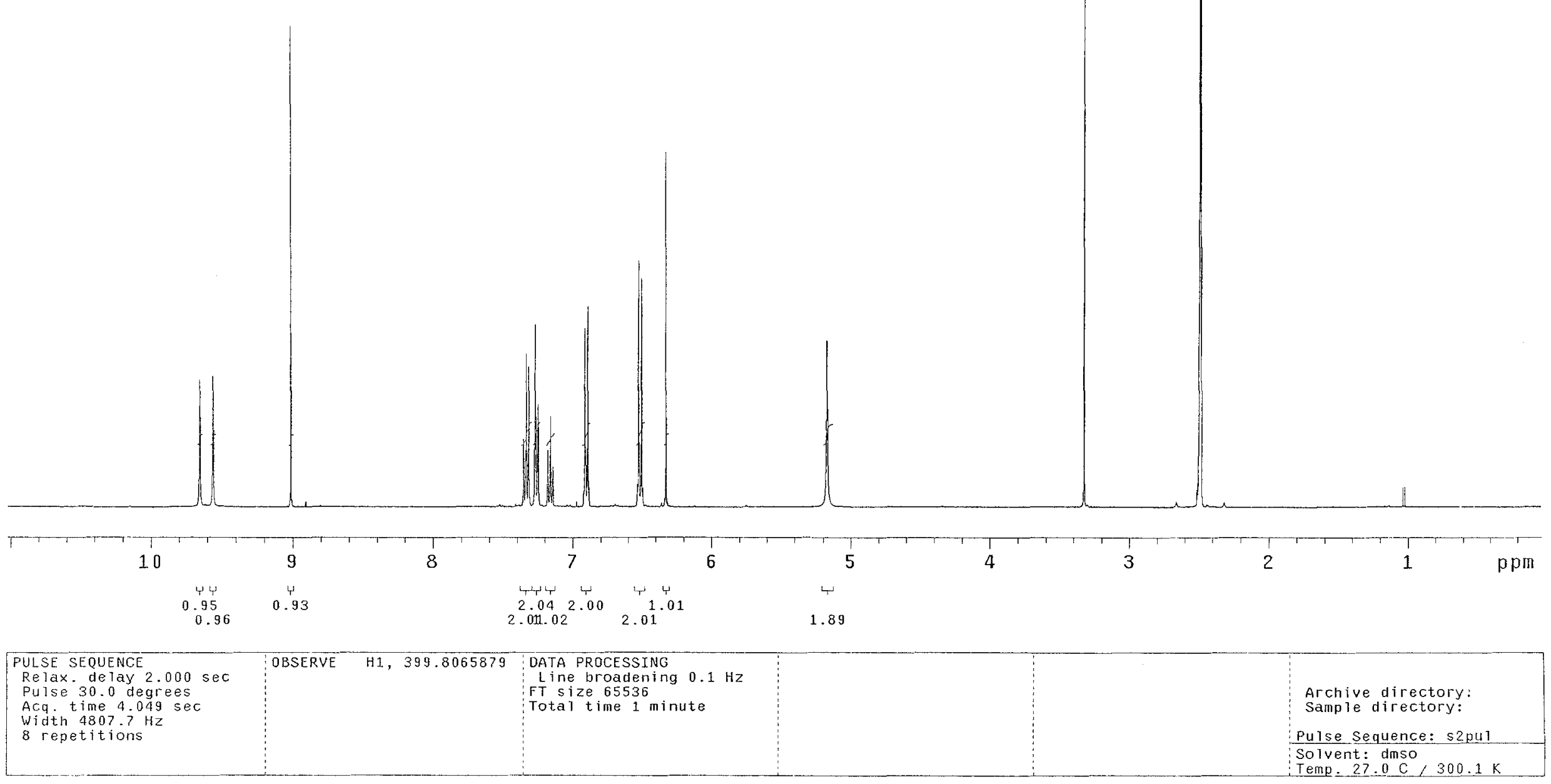



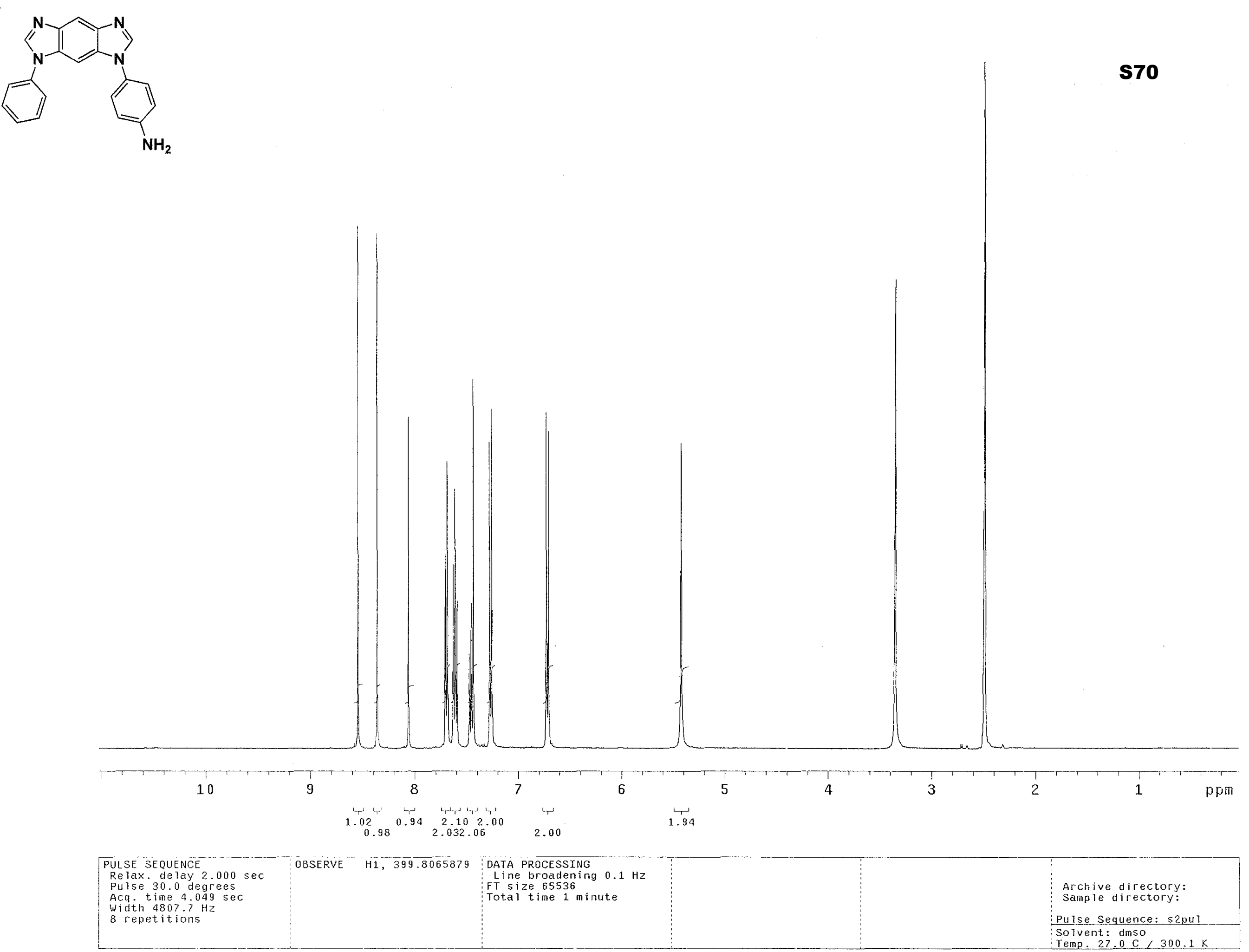

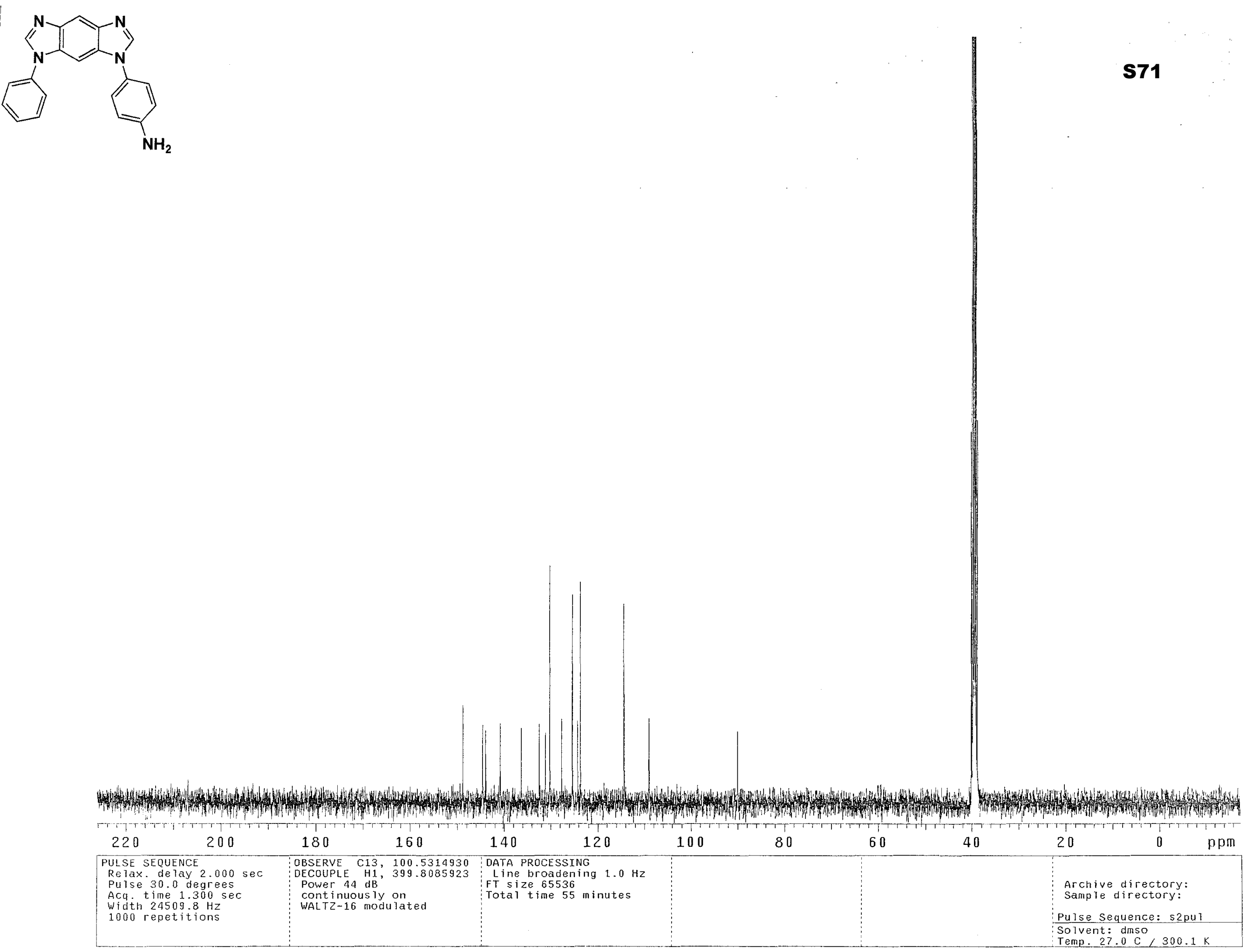

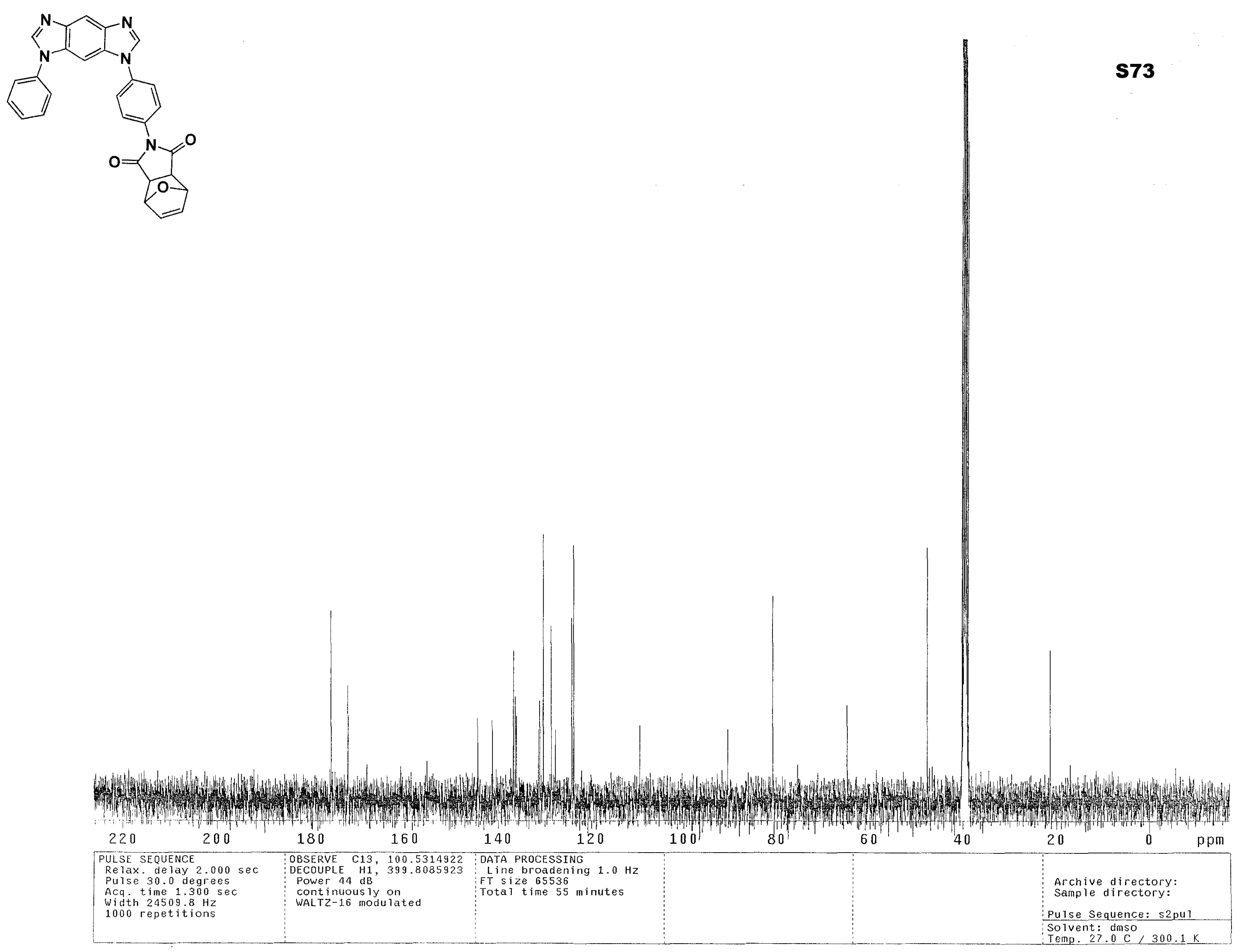


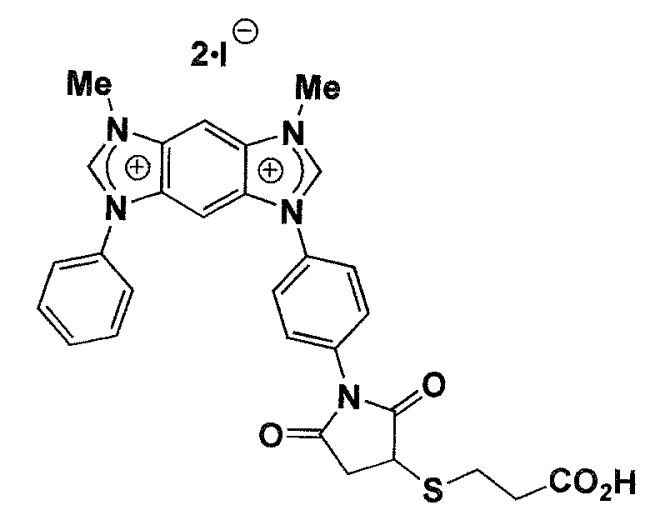

\section{S76}

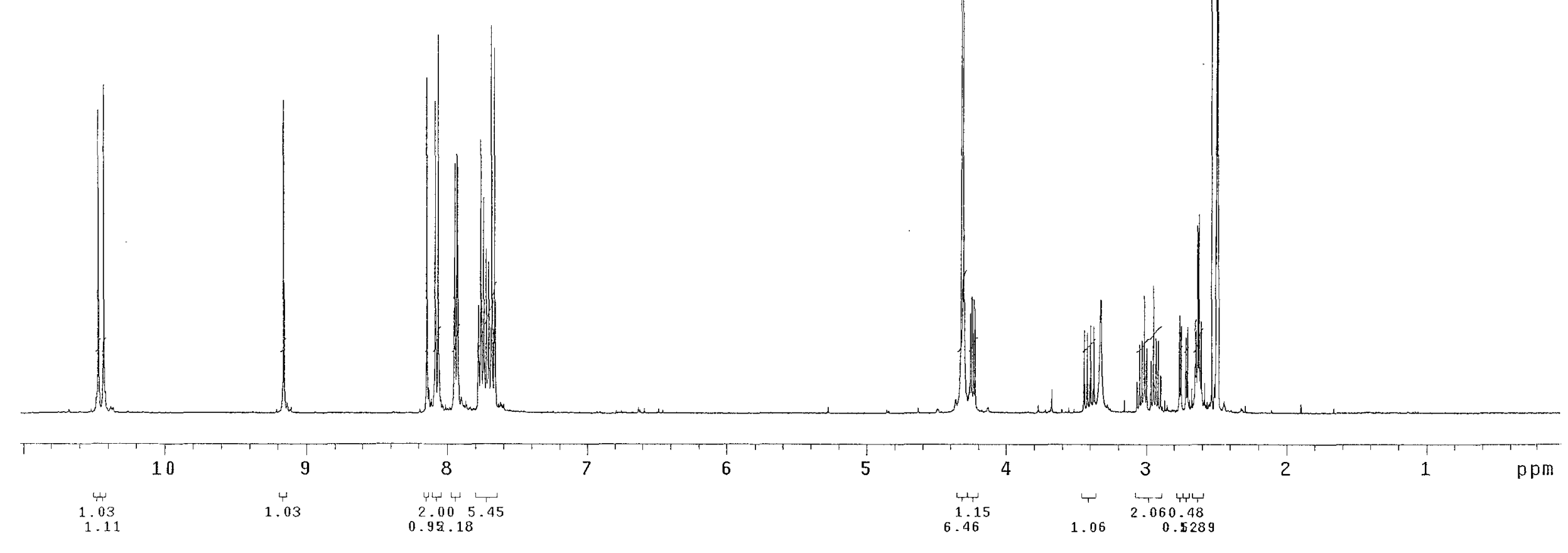

\begin{tabular}{|c|c|c|c|}
\hline $\begin{array}{l}\text { PULSE SEQUENCE } \\
\text { Relax. delay } 2.000 \mathrm{sec} \\
\text { Pulse } 30.0 \text { degrees } \\
\text { Acq. time } 4.049 \text { sec } \\
\text { Width } 4807.7 \mathrm{~Hz} \\
\text { 8 repetitions }\end{array}$ & OBSERVE H1, 399.8065878 & $\begin{array}{l}\text { DATA PROCESSING } \\
\text { Line broadening } 0.1 \mathrm{~Hz} \\
\text { FT } 5 \text { ize } 65536 \\
\text { Total time } 1 \text { minute }\end{array}$ & $\begin{array}{l}\text { Archive directory: } \\
\text { Sample directory: } \\
\text { Pulse Sequence: s2pul } \\
\text { Solvent: dmso } \\
\text { Temp. 27.0 C } 300.1 \mathrm{~K}\end{array}$ \\
\hline
\end{tabular}



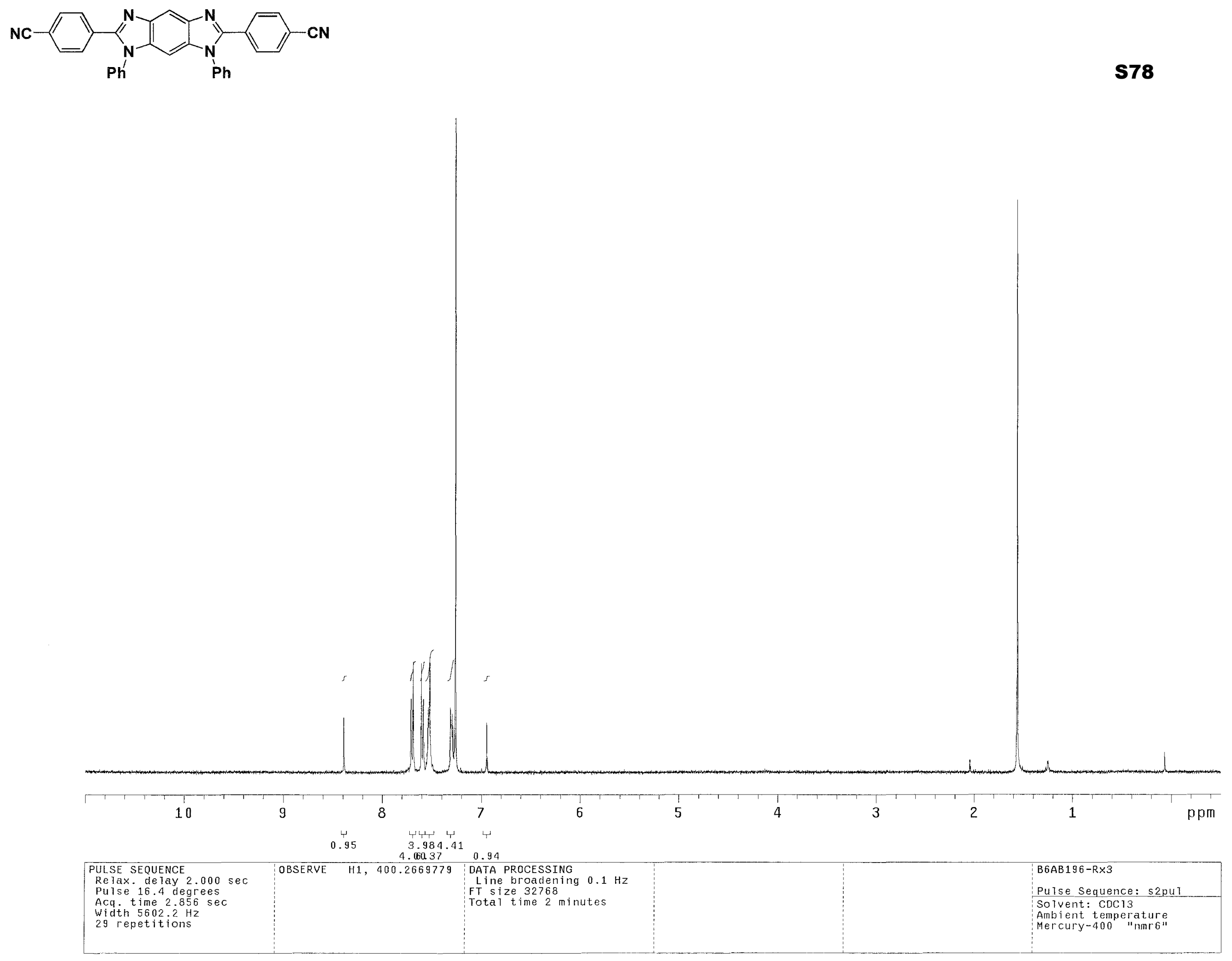


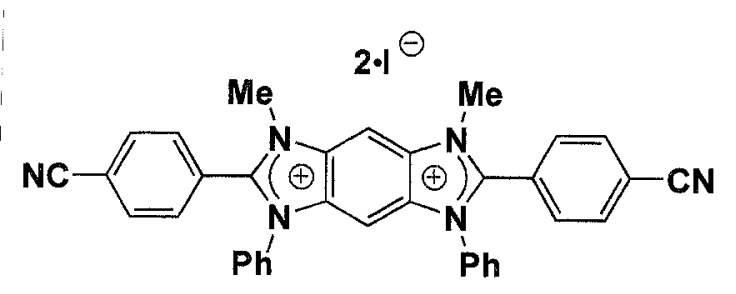

580

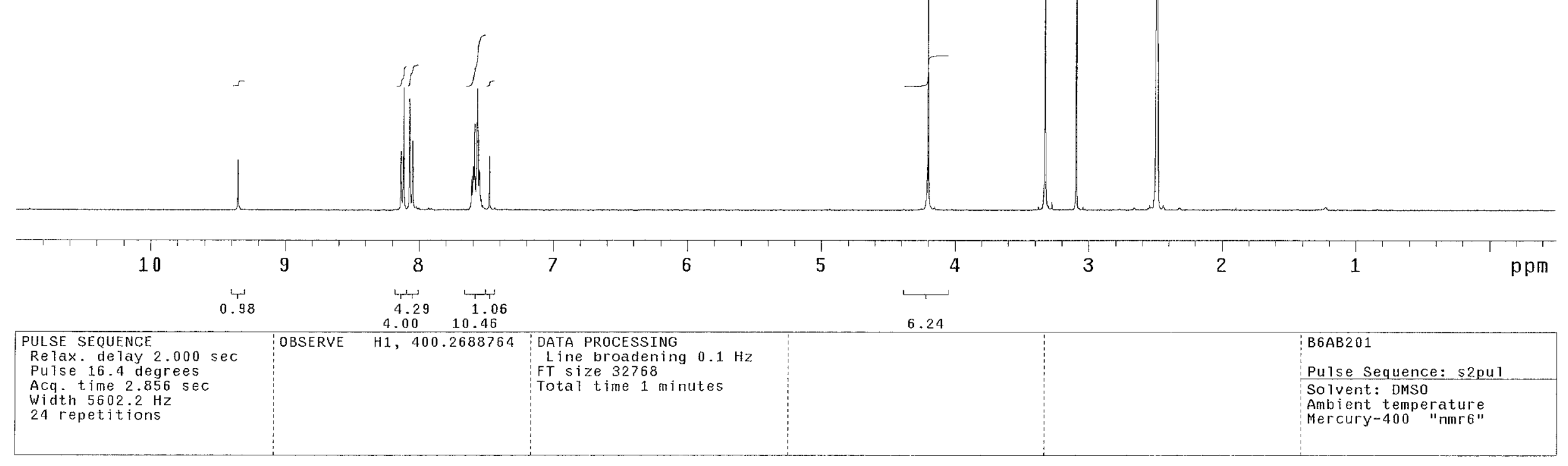


